Spring 6-8-2021

\title{
An Occupation-Based Program to Promote Mental Health of At- Risk Youth in an After-Care Setting
}

\author{
Alexa Smith \\ University of St. Augustine for Health Sciences \\ DOI: https://doi.org/10.46409/sr.AVGN4830
}

Follow this and additional works at: https://soar.usa.edu/capstones

Part of the Community Health Commons, Occupational Therapy Commons, and the Social Justice Commons

\section{Recommended Citation}

Smith, A. (2021). An Occupation-Based Program to Promote Mental Health of At-Risk Youth in an AfterCare Setting. [Doctoral project, University of St Augustine for Health Sciences]. SOAR @ USA: Student Capstone Projects Collection. https://doi.org/10.46409/sr.AVGN4830

This Capstone is brought to you for free and open access by the Student Research at SOAR @ USA. It has been accepted for inclusion in Student Capstone Projects by an authorized administrator of SOAR @ USA. For more information, please contact soar@usa.edu, erobinson@usa.edu. 
Spring 6-8-2021

\section{An Occupation-Based Program to Promote Mental Health of At- Risk Youth in an After-Care Setting}

Alexa Smith

Follow this and additional works at: https://soar.usa.edu/capstones

Part of the Community Health Commons, Occupational Therapy Commons, and the Social Justice Commons 
An Occupation-Based Program to Promote Mental Health of At-Risk Youth in an AfterCare Setting

\author{
Alexa B. Smith \\ Department of Occupational Therapy, University of St. Augustine for Health Sciences
}

A Capstone Presented in Partial Fulfillment

of the Requirement for the Degree of DOCTOR OF OCCUPATIONAL THERAPY

University of St. Augustine for Health Sciences

April, 2021 
An Oceupation-Based Program to Promote Mental Health of At-Risk Youth in an After-

\title{
Care Setting
}

\author{
Alexa B. Smith \\ Department of Occupational Therapy, University of St. Augustine for Health Sciences \\ has been approved \\ April 2021
}

APPROVED:

Pamela Kasyan-Howe, OTD, OTR/, Doctoral Coordinator

Kristin Domville, Dr.OT, OTR/, Doctoral Coordinator

Joso Rafols, OTD, MHSA, OTR/L, BCTS, CEAS, Program Director

ACCEPTED AND SIGNED: 
Table of Contents

Chapter 1: Introduction ..........................................................

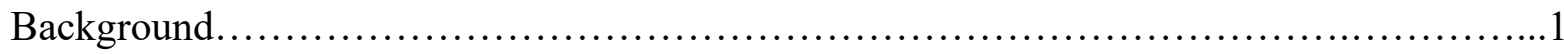

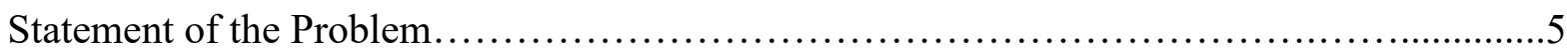

Purpose Statement..............................................................

Rationale......................................................................

Significance.............................................................

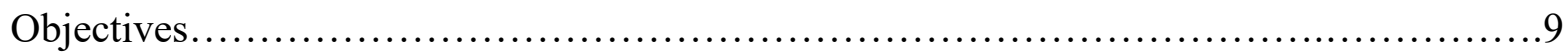

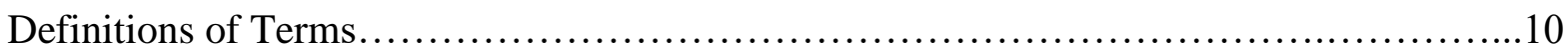

Assumptions, Limitations, and Delimitations.................................. 11

Chapter 2: Literature Review..........................................................

The School-to-Prison Pipeline.................................................... 14

Risk Factors for the School to Prison Pipeline..................................... 17

The Need to Increase Mental Health Services for At-Risk Youth.........................19

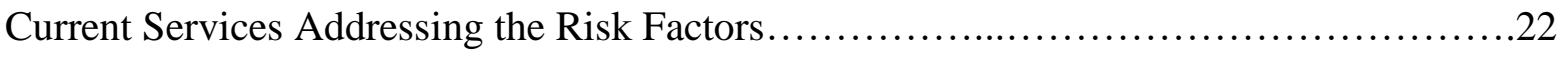

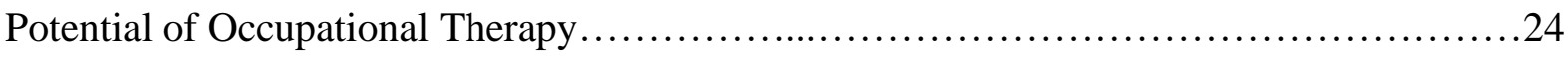

Mental Health Defined for the Project's Program..................................... 31

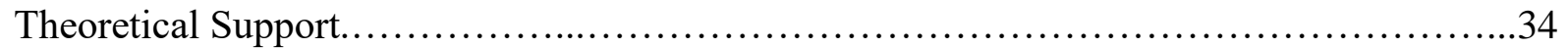

Conclusion................................................................... 36

Chapter 3: Project Description....................................................... 38

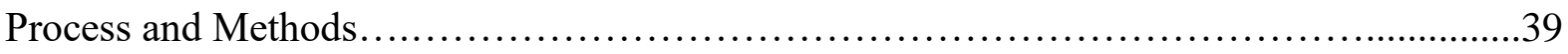

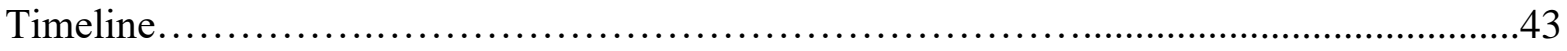

Conclusion and Next Steps.................................................46 
Chapter 4: Results and Analysis.............................................. 48

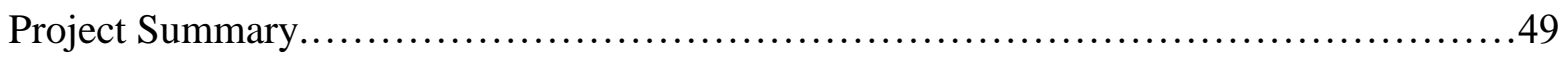

Project Outcomes.........................................................54

Conclusion....................................................................64

Chapter 5: Discussion and Conclusion............................................... 67

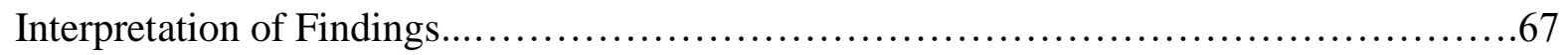

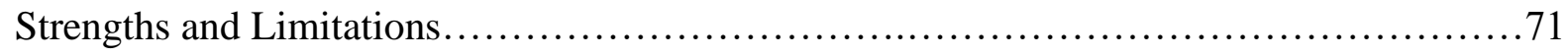

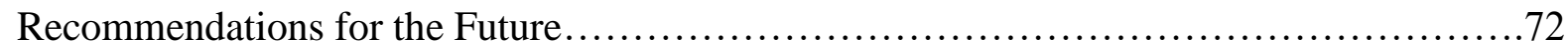

Conclusion.....................................................................

References............................................................. 74

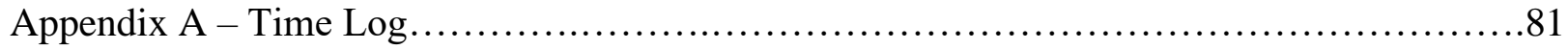

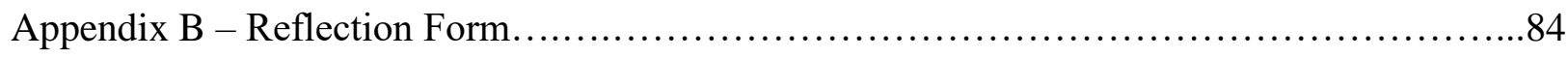

Appendix C - Certificate of Completion.......................................... 85

Appendix D - Program Session Manual............................................... 86 
Copyright (C) Alexa B. Smith, 2021 all rights reserved 


\section{Chapter I: Introduction}

\section{Background}

Youths between the ages of 5-18 identified as at risk within the school system have an increased tendency to become incarcerated (Mallet, 2016; Mallet, 2017). In many school districts across the United States during 2012, youths were more likely to be arrested at school than they were a generation ago. Between the 2011-2012 school year, the number of in-school suspensions was 3.5 million students, the number of out-of-school suspensions was 3.45 million, and the number of students expelled from school was 130,000 (U.S. Department of Education, 2016). The 2016 Digest of Education Statistics reports that 20\% of all public-school students and $48 \%$ of black male students in grades 6-12 were suspended at least once by 2012 (National Center for Education Statistics 2016). The disproportionate tendency for young adults from disadvantaged backgrounds to shift from schools to the juvenile justice system is referred to as the "school to prison pipeline" and affects upwards of $2.4 \%$ of all elementary-aged students and $11.3 \%$ of all secondary-school-aged students (Mallet, 2017).

Societal events and policy changes over the past five decades created the phenomena defined in the literature as the school to prison pipeline (Mallet, 2016; Wiley et al., 2018). Starting in the 1970 s, school system policies on disciplinary action began to shift from more lenient to more strict policies that many youths today face. These actions to date include inflexible discipline codes, security cameras, school resource officers, in-school suspensions, suspensions, expulsions, and transitions to juvenile justice facilities. The phenomenon is attributed to three main factors that have resulted in the paradigm shift: in-school suspensions, the increased perception of youth violence in the media, and the implementation of security measures as a result of numerous school shootings. The influence of these zero-tolerance strict 
disciplinary actions that result in a resemblance of prison-like school environments are far reaching and impact students across the entire United States (Mallet, 2016).

The prison-like school environment shifted the trust and comfort that youths have with facility and staff and further impacted academic performance across the county (Mallet, 2017). Observing the overall impact on zero-tolerance policies and the criminalization of education for youths, two groups of students are consistently more affected than any other group: minorities and individuals living in poorer communities. School districts that are disproportionately poor and have a large minority population are found to be more likely to utilize security measures and to have police officers in their schools resulting in negative reactions, fears, and worries about their school (Wiley et al., 2018). While the implementation of zero-tolerance policies can affect all youths, the subsequently smaller number caught within the school to prison pipeline share commonalities and experiences that place them at higher risk for these outcomes (Mallet, 2017).

A multitude of comorbid factors that lead to offending behaviors and incarceration are often found in youths who enter the school to prison pipeline. Comorbidity of factors describes involvement with the juvenile courts as a result of a combination of risk factors, rather than any one single experience (Mallet, 2017). Comorbid factors for involvement in the school to prison pipeline include poverty, family dysfunction, violence, trauma, academic and learning problems, mental health difficulties, and unstable and disorganized urban neighborhoods. While few risk factors can be modified, mental health difficulties are often treated by many different psychological and rehabilitative disciplines, including occupational therapy.

Occupational therapists around the country currently work with students in many different settings who have a variety of special education disabilities that often include mental health difficulties (Boyt Schell \& Gillen, 2019; Burson et al., 2017). Occupational therapy (OT) 
is the client-centered therapeutic use of everyday life activities, or occupations with individuals and groups that facilitate participation in roles, habits, and routines across all settings (AOTA, 2020). OT practice utilizes eight areas of occupations when working with individuals or groups to target and treat deficits in relation to mental and physical deficits. The areas of occupations include: activities of daily living (ADLs), instrumental activities of daily living (IADLs), rest and sleep, education, work, play, leisure, and social participation.

Mental health is defined as a state of well-being in which a person realizes his or her abilities, copes with challenges, and is able to work and contribute to the community (World Health Organization, 2013). Occupational therapists bring a perspective of rehabilitation to mental health services keeping a large emphasis on recovery and wellness directed toward independent participation in daily life occupations (Burson et al., 2017). Children with mental health deficits typically receive OT services in hospitals, community mental health treatment settings, private therapy clinics, domestic violence and homeless shelters, schools, day care centers, and other early education programs (Mahaffey, 2016). The overall goal for OT practitioners providing mental health services is to promote participation in occupations that a crucial for a healthy childhood and set the child up for success throughout their lifetime.

Looking specifically at the population of at-risk youth, the occupations impacted due to mental health deficits include education, work, play, leisure, and social participation (Ryan, 2019). Two specific settings that aim to increase engagement in these occupations include the public-school setting and the after-care setting. While the public-school setting is required to provide special education services to students who are found eligible under the Individuals with Disabilities Education Act (Harmon, 2020), the after-care setting shows a significant need to 
increase therapeutic services addressing mental health needs (Cahill et al., 2020; Greenberg et al., 2017; National Council on Disability, 2015; Yoder et al., 2017).

After-care programs around the country currently aim to reduce problem behaviors and improve academic performance through engagement in structured courses and activities after the typical school day has ended (Jenson et al., 2018). While the results of studies examining the effects of after-care programs on at-risk youth show improvements in the youths' overall academic performance, there is still a need for additional focus on client-centered mental health treatment (Tokolahi et al., 2016; Shea \& Jackson, 2019). Occupational therapists have an opportunity for identifying and treating underlying mental health difficulties experienced due to any number of comorbid risk factors within a natural environment for the youth. Working with at-risk youth in after-care programs through an OT lens with support from current OT models will provide an alternative and therapeutic approach to increase engagement in the traditional occupations for youth.

Occupation-based models serve as overarching or umbrella theories the profession of OT uses to explain the relationship of occupation, person, and environment (Cole \& Tufano, 2008). The models do not focus on any specific age or disability but rather apply to all people. Occupation-based models guide OT practitioners when selecting evaluations and assessments for a particular group or practice area. The models can be used independently, in conjunction with other models, or in conjunction with frames of reference. While models provide overarching guidance, frames of reference provide more specific guidance on intervention for a specific age or disability. The proposed project is anchored by two distinct models in order to frame the goals and provide a more in depth analysis of both the population and setting level. 
The Ecology of Human Performance (EHP) and Person-Environment-OccupationPerformance (PEOP) models focus on each individual client's needs and interests and authors have used these models to frame the understanding of this population (Brown, 2019). These models provide a broader perspective to accommodate the host facility's needs and provide a foundation for the project's development. The EHP model focuses on the role of context and environment in overall task performance (Dunn et al., 1994). The EHP model will be applied in group sessions to analyze the effectiveness of the program to establish occupation-based opportunities for mental health growth. The PEOP model focuses on how the intersection of occupations, environment, and person factors create the opportunity for occupational performance (Baum \& Christiansen, 2005). The use of the PEOP model will be applied to the project to develop and implement and occupation-based program to address mental health at the individuals, group, and organizational level. Overall, the project is designed to collaboratively develop an occupation based program addressing mental health and social competence difficulties within an after-care setting for at-risk youth.

\section{Statement of the Problem}

The problem is a lack of supporting services addressing mental health and occupational performance provided to at-risk youth in after-care settings. Legislative and policy changes within school districts over the last 5 decades resulted in harmful effects for social and academic performance within the school setting (Mallet, 2016). The harmful effects of these changes impact the youth that are at a predisposed greater risk for incarceration and include minority and financially disadvantaged populations. The policy changes and predisposed risks have together caused an increase in the number of youths who come in contact with the juvenile justice system through the school to prison pipeline. While many after-care programs across the country aim to 
prevent youths from entering the school to prison pipeline, many lack effective therapeutic alternatives for mental health treatment and overall occupational performance (Shea \& Jackson, 2019; Tokolahi et al., 2016).

\section{Purpose Statement}

The purpose of the program development type project is to increase the supportive mental health services provided to at-risk youth in the after-care setting. The proposed project will fulfill the need for additional services addressing mental health deficits within this setting and show the unique contribution the profession of OT can make for this population. The project will utilize OT group therapy techniques to involve and encourage youths in weekly, 1 hour sessions at MaliVai Washington Youth Foundation (MWYF) and the DuPont YMCA to promote and facilitate the skills needed to improve mental health and occupational performance. The project will encourage participants to engage in sessions addressing management of positive and negative emotions, mindfulness techniques, emotional learning, bullying prevention, time management and organization skills, character strength building, social skills training, conflict resolution skills, and communication. The project will analyze information on the demographics of the youth at the facility location to further tailor sessions and materials to the specific target audience. The project materials will provide the resources, materials, education, and confidence needed to engage in healthy occupations for at-risk youth and improve overall occupational performance. The program session will be structured with the use of Cole's Seven Step organizational model while resources and materials will be bolstered by the use of the EHP and PEOP occupation-based models as well as current literature and documents published from AOTA.

\section{Rationale}


The rationale for the project is to create effective therapeutic components addressing mental health to integrate into after-care programs for at-risk youth and decrease the number of youths entering the school to prison pipeline. Increasing the amount of services provided to atrisk youth in urban areas can both increase engagement in typical occupations of youth and decrease the overwhelming number of these youths in the juvenile justice system. The project will contribute to the youth, the facility, the profession of OT, and the local community. The project contributes to the at-risk youth in after-care settings by providing education on strategies to handle stress and/or anger, increase self-confidence through social interaction with peers, and encourage open and honest communication with authority figures. The host facility will benefit from the proposed research project by gaining information about the program on the effectiveness and level of interest in preventative mental health group sessions. Following the termination of the project, the facility can implement these sessions in the curriculum in the future and increase their students' occupational performance.

The project also contributes to the OT profession by creating additional programs to support OT services in after-care programs. The addition of at-risk youth as an emerging area of practice within OT provides another setting in which OT practitioners can educate and integrate common practices into the general population. Society, too, would benefit from the addition of this project by reducing the amount of youths that come in contact with the juvenile justice system. Equipped with education and strategies used to handle difficult situations, youths will be more prepared to deal with the stresses of everyday life in and out of school that will further decrease their changes of entering the school to prison pipeline.

\section{Significance}


The project fills the gap of lack of services in after-care settings by developing, evaluating, and disseminating a program that addresses the mental health needs of at-risk youth in this setting. The current literature, although limited, shows the impact OT programs in particular can have on youths' perception of themselves, their surroundings, and their futures. By providing additional services and effective therapeutic options for individuals who may not otherwise have the opportunity in their environment, OT allows for exploration and development of nonacademic skills needed for everyday living. The skills learned in the proposed mental health groups can be generalized to other settings in these youth's lives including home or school.

Youths will be given the opportunity to build crucial skills and boost their overall selfesteem and self-efficacy to approach the school environment with new strategies and perspectives. In addition to helping at-risk youth engage in age appropriate roles and occupations, the proposed project will acquire information on the qualitative perspective youths' have on the group sessions through weekly reflections. Over the course of the 14 weeks, determining the impact of group sessions addressing mental health of at-risk youth at MWYF and the DuPont YMCA in Jacksonville, Florida will allow for multiple different perspectives to be collected and analyzed in this setting. The project aims to show the value the field OT can have on increasing mental health services to at-risk youth in after-care settings through use of the organizational Cole’s Seven Step group therapy model (Cole, 2018).

The profession of OT has an opportunity to support services within this setting revolutionizing the way after-care programs are run. A focus on group sessions could target many occupations youths are experiencing barriers to including work, education, play, leisure, and social participation. The after-care community setting is an excellent target for OT as all 
methods of intervention could be utilized for the benefit of both the facility and the youths participating including occupations, activities, education, training, advocacy, self-advocacy, and groups (AOTA, 2002). Significant results from the proposed project could benefit the profession of OT by providing a setting to treat mental health deficits that can and should be addressed in after-care settings. This project develops a program that can be used to show the need to increase the amount of research done for this population and setting. The project is significant for the field of OT because it will develop a program to address mental health treatment in a practice setting with disadvantaged populations. The project is significant for after-care providers and the youths that attend after-care to provide them with the curriculum needed to combat the school to prison pipeline. The project is significant for society overall to further limit the amount of youths who come in contact with the juvenile justice system today.

\section{Objectives}

Learning Objectives:

- Compare and contrast the demographics of youth at the host facilities with the current literature

- Compare and contrast services provided to at-risk youth at two after-care centers

- Compare and contrast services provided to at-risk youth in the after-care setting to other settings that serve this population

- Assess relevance of group topics to students at host facilities

- Apply understanding of staff trainings for child abuse and mandated reporting in sessions Outcome Objectives:

- Implement group sessions targeting mental health to youth at host facilities

- Educate youth on recognizing and coping with positive and negative emotions 
- Educate youth on appropriate social and relationship building skills

- Promote youths' self-confidence and personal strength identification

- Promote academic achievement through the development of necessary life skills

- Acquire and review program feedback on group session effectiveness, level of interest, and future suggestions from at-risk youth

\section{Definition of Terms}

After-care setting- structured programs supervised by adults and operate after school during the school year. Unlike extra-curricular activities that also often occur after school, such as sports or academic clubs, after-school programs are comprehensive programs offering an array of activities that may include play and socializing activities, academic enrichment and homework help, snacks, com- munity service, sports, arts and crafts, music, and scouting (Jenson et al., 2018).

At-risk youth- a child who is less likely to transition successfully into adulthood. Success can include academic success and job readiness, as well as the ability to be financially independent. It also can refer to the ability to become a positive member of society by avoiding a life of crime (National Council on Disability, 2015).

Community-based- occupational therapy services being provided in community settings such as after school program, church organization, etc (Boyt Schell \& Gillen, 2019).

Mental Health- state of well-being in which a person realizes his or her abilities, copes with challenges, and is able to work and contribute to the community (World Health Organization, 2013). 
School to prison pipeline- the disproportionate tendency of minors and young adults from disadvantaged backgrounds to become incarcerated, because of increasingly harsh school and municipal policies (National Council on Disability, 2015).

Self-advocacy- the action of representing oneself or one's views or interests (Boyt Schell \& Gillen, 2019).

Zero-tolerance policies- philosophy or policy that man-dates the application of predetermined consequences, most often severe and punitive in nature, that are intended to be applied regardless of the apparent severity of the behavior, mitigating circumstances, or situational context. Such an approach is intended to deter future transgressions, by sending a message that no form of a given unacceptable behavior will be tolerated under any circumstances (Mallet, 2016).

\section{Assumptions, Limitations, and Delimitations}

A current limitation to the proposed project is the structured nature of existing after-care programs. While many programs currently target the occupation of education, there seems to be a strict schedule to which the staff and participants follow over the course of the program. After conducting a thorough needs assessment with the host facility, the proposed project will find means of collaboration and partnership with already existing sessions. Another limitation the project faces is the unprecedented circumstances presented to both the students and facility due to the pandemic of COVID-19. The pandemic has displaced students out of schools and back into their homes, therefore, decreasing the number of students currently in the after-care setting. The pandemic has also added the component of social distancing to the setting limiting the amount of staff and students that can be together in close proximity to one another during sessions. The project intends to take these conditions into consideration and diligently work 
around them by implementing an effective program to address the mental health needs of the students adhering to recommendation of health officials due to COVID-19.

The proposed project has been developed under the assumption that the participants in the group sessions will be present every day. The participants come from their school environment directly to the after-care center and therefore should be present during each session. Another assumption of the project is that the students will be honest and accurate in their feedback responses. The project assumes that the students will honestly report their level of interest effectiveness of each group session.

One delimitation the project intends to control over the course of the program is the demographics of the participants. The project has identified the participants of the group session as at-risk through collaboration with facility staff. The participants all share similar risk factors including socio-economic status, mental health difficulties, and low academic success that make them eligible for the program. Eligibility was determined through a thorough literature review on the phenomena of the school to prison pipeline, risk factors for the school to prison pipeline, and the possible potential of occupational therapy. 


\section{Chapter II: Literature Review}

At-risk youth in the community often experience a lack of supporting services addressing mental health (Cahill, 2020). Legislative and policy changes within school districts over the last 5 decades has resulted in harmful effects for social and academic performance within the school setting (Mallet, 2016). The harmful effects of these changes predominately impact youths that are at a predisposed greater risk for incarceration: minority populations and youths living in urban areas. The policy changes and predisposed risks have together caused an increase in the number of youths who come in contact with the juvenile justice system through the school to prison pipeline (Mallet, 2017). While many after-care programs across the country aim to prevent youths from entering the school to prison pipeline, many lack efficient therapeutic alternatives for mental health treatment (Shea \& Jackson, 2015, 2019).

The school to prison pipeline is a novel phenomenon that continues to be researched and explored with an aim to break the vicious cycle and improve the future for at-risk youth. An influential change in structure that could potentially break or slow the cycle is introducing and increasing the number of rehabilitative programs in schools, aftercare programs, and juvenile courts (Mallet, 2017). Currently, many after-care programs focus solely on academic benefits to youths in impoverished neighborhoods, while glossing over mental health needs and social growth. When analyzing the goals set out by after-care programs, $93.6 \%$ of centers set academic improvements as a goal, but only $15.4 \%$ of centers met this goal. Outside of academic achievement, $69.3 \%$ of centers listed positive behavior change as a goal, with only $19.8 \%$ of centers meeting this goal (Kremer et al., 2015). Lacking therapeutic alternatives and goals outside of academic achievement limits youths' occupational performance, and neglects the comorbidities that often result in the school to prison pipeline. 
The overarching problem at-risk youth face is a lack of supporting mental health services in the after-care setting. The purpose of the program development type project is to increase the supportive mental health services to at-risk youth in the after-care setting. The proposed project will fill the gap for additional services addressing mental health deficits within this setting and show the unique contribution the profession of OT can make for this population. The literature review will describe current literature to support the problem and purpose of the proposed project. The review will include the development and current status of the school to prison pipeline, leading risk factors for the school to prison pipeline, the need to increase mental health services, current services addressing the risk factors, the potential of OT, mental health defined for the project's program, and the theoretical support for the project.

\section{The School-to-Prison Pipeline}

Youths identified as at risk within the school system have an increased tendency to become incarcerated (Schiff, 2018; Mallet, 2016, 2017). In many school districts across the United States during 2012, youths were more likely to be arrested at school than they were a generation ago, and the number of students suspended from school each year has nearly doubled from 1.7 million in 1974 to 3.1 million in 2000 (Schiff, 2018). Between the 2011-2012 school year alone, the number of in-school suspensions was 3.5 million students, the number of out-ofschool suspensions was 3.45 million, and the number of students expelled from school was 130,000 (U.S. Department of Education, 2016). The disproportionate tendency for young adults from disadvantaged backgrounds to shift from schools to the juvenile justice system is referred to as the school to prison pipeline and affects upwards of $2.4 \%$ of all elementary-aged students and $11.3 \%$ of all secondary-school-aged students (Mallet, 2017). 
Societal events and policy changes over the past five decades created the phenomena defined in the literature as the school to prison pipeline (Mallet, 2016). Starting in the 1970s, school system policies began a slow shift toward strict disciplinary actions many youths come in contact with today. These actions to date include inflexible discipline codes, security cameras, school resource officers, in-school suspensions, suspensions, expulsions, and transitions to juvenile justice facilities. The phenomenon is attributed to three main factors that have resulted in the paradigm shift: in-school suspensions, the increased perception of youth violence in the media, and the implementation of security measures as a result of numerous school shootings. The influence of these policies and strict disciplinary actions are far reaching and impact students across the entire United States (Mallet, 2016).

The first factor that has influenced the shift to strict disciplinary action is the transition from corporal punishment to in-school suspensions (Mallet, 2016; Wiley et al., 2018). Dating back to the 1960s and 1970s when remnants of corporal punishment were still used as means of classroom management, school populations were on the rise and these means quickly became unacceptable and ineffective. Suspensions and expulsions became the new methods for managing disruptive students within schools until the Goss v. Lopez Supreme Court decision in 1975 found due process violations in the suspension and expulsion of students without hearings (419 U.S. 565, 1975). As a result, schools turned to in-school suspensions to remove the students from the classroom but keep them inside the school to complete all classwork (Mallet, 2016). The in-school suspensions were seen as rehabilitative efforts for managing disruptive students and were favored by most school administrators through the 1980s until a shift toward mandatory disciplinary outcomes resulted from other co-occurring factors (Mallet, 2016). 
The second factor that influenced the shift towards strict disciplinary actions within schools was the increased perception of youth violence in the media (Mallet, 2016). During the 1980s and 1990s, many young people were portrayed as violent for committing horrific crimes and engaging in gang violence in the media. According to the researchers, the portrayal was entirely disproportionate to the reality of youth violence and state and federal legislative policies were developed regardless to increase punitive disciplines for youths within schools. Resulting legislation included trying more youth as adults, expanding the severity of penalties, and minimizing rehabilitative alternatives. Although 1994 did see the peak of the commission of violent crimes by young people, the rates have decreased significantly within the past two decades. While the rates have decreased, the policy changes continued to be enforced and therefore set the stage for further control and discipline across all school districts.

Leading into the 2000s, the third factor that contributed to the overall shift to strict disciplinary action in schools was the introduction of security measures that came as a result of previous school shootings that took place. The 1990s and 2000s saw many school shootings including Columbine High School, Bethel Regional High School, Pearl High School, Health High School, Frontier Middle School, and Thurston High School that resulted in further policy changes (Newman \& Hartman, 2019). The Gun-Free Schools Act became the next piece of legislation that acted as a seal of approval to promoting zero-tolerance policies in school districts (Mallet, 2016). While this act prohibited the possession of a gun on school grounds, subsequent amendments expanded the act to prohibit violent behavior, fighting, assault, harassment, indecent exposure, vandalism, destruction of school property, verbal harassment, disobedience, obscene language, and truancy. Security guards, metal detectors, police officers working in the buildings, and surveillance cameras were implemented to enforce the zero-tolerance policies. 
The security measures created more of a prison-like environment than a safe school environment for youths.

The prison-like school environment shifted the trust and comfort that youths have with facility and staff and further impacted academic performance across the county (Wiley et al., 2018). Observing the overall impact on zero-tolerance policies and the criminalization of education for youths, two groups of students are consistently more affected than any other group: minorities and individuals living in poorer communities. School districts that are disproportionately poor and have a large minority population are found to be more likely to utilize security measures and to have police officers in their schools resulting in negative reactions, fears, and worries about their school. While the implementation of zero-tolerance policies can affect all youths, the subsequently smaller number caught within the school to prison pipeline share commonalities and experiences that place them at higher risk for these outcomes.

\section{Risk Factors for the School to Prison Pipeline}

While certain risk factors can make a child more likely to perform poorly in school, there are also risk factors that are found among youth who more likely to commit offending crimes and come in contact with the juvenile justice system (Mallet, 2017). A multitude of comorbid factors that lead to offending behaviors and incarceration are often found in youths who enter the school to prison pipeline. Comorbidity of factors describes involvement with the juvenile courts as a result of a combination of risk factors, rather than any single experience. Comorbid factors for involvement in the school to prison pipeline include poverty, family dysfunction, violence, trauma, academic and learning problems, mental health difficulties, and unstable and disorganized urban neighborhoods. 
Poverty has an impact on educational performance and outcomes for all children, and more than one in five children grow up in poverty (Mallet, 2017). All children, minority and Caucasian, who live in poverty are more likely to start school academically behind their peers and less likely to graduate from high school. Of children who are living in poverty, children of color are disproportionately poor and often fare worse than nonminority children. Along with poverty, maltreatment significantly affects a childs abilities to learn, decreases cognitive and language capacities, increases risk of special education disabilities, and decreases standardized testing outcomes. Families of children who are living in poverty and have high rates of violence have more difficulty finding and accessing safe housing and securing mental health care for their children.

Mental health difficulties make up the highest number of youths overrepresented in the school to prison pipeline (National Council on Disability, 2015). Eighty-five percent of youths in juvenile detention facilities have disabilities that make them eligible for special education services, yet only $37 \%$ receive those services in school. While federal legislation such as the Individuals with Disabilities Education Act (IDEA, 2004) attempts to keep students with special education disabilities in public education, many of these students are not getting the appropriate mental health services and therefore demonstrate poorer outcomes in school and are suspended and expelled more often than their peers without disabilities (Harmon, 2020). While the IDEA provides special education services to students with special education disabilities, this population is 2 times more likely to be suspended or expelled from school compared to their peers, limiting involvement in specialized services (Mallet, 2017).

Students with certain mental health problems, diagnosed under the IDEA as an emotional disturbance, are found to be more likely to receive school discipline within the special education 
student population (Mallet, 2017). African American students within this population, are even more at risk with significantly higher rates of suspensions and expulsions. This specific population is more likely to be placed in a restrictive setting, have higher dropout rates, and 50\% have at least one arrest as young adults. Due to the high prevalence of emotional disturbance and mental health deficits in juvenile detention facilities, measures should be taken to provide early preventative mental health treatment to at-risk youth in settings which serve this population (Jamie et al., 2017).

\section{The Need to Increase Mental Health Services for At-Risk Youth}

More than 2 million children, adolescents, and young adults come in contact with the juvenile justice system in the United States alone (Zajac et al., 2015). Upwards of $70 \%$ of this population experiences at least one diagnosable mental health problem, yet the current rehabilitation system fails to meet the needs of these individuals. Many individuals who are eligible to receive services within the school system are often suspended and/or expelled due to harsh disciplinary actions and therefore no longer receive those services. Even outside of the school system, many after-care programs that assist at-risk youth in academic development do not have effective mental health treatment (Cahill et al., 2020). A portion of this population which is classified into a developmental period known as the transition age, ages 16-25, often show signs of mental health disturbances that were not treated during the younger school-age years (Zajac et al., 2015).

Rates of mental health problems peak during the transitional age from late teens to early 20's, when many youths come in contact with the juvenile justice system, but also when mental health services decline sharply (Zajac et al., 2015). A study examining evidence-based domainspecific practices found that a focus on mental health treatment, substance abuse treatment, and 
educational and vocational supports provided in wraparound services, diversion programs, and after-care programs were key to addressing youths' mental health through alternative rehabilitation prior to involvement in the juvenile justice system. While this study provides effective evidence-based practices that can be used to address youths' mental health prior to involvement in the juvenile justice system, current literature bolsters the need for mental health services in settings youths engage in prior to juvenile justice settings.

In an attempt to determine the mental health symptoms of early system-involved youth referred to a juvenile diversion program, one study measured each juvenile's presenting symptoms at the time of their assessment (Wylie \& Rufino, 2018). The results of the study show that two thirds of the early system-involved juveniles experience one or more mental health symptoms, with one in five reporting substance use or mood symptoms, one in three reporting anxiety symptoms, and almost half reporting disruptive disorder symptoms. When compared to already incarcerated juveniles, it appeared that early system-involved juveniles experience similar mental health symptoms. The results of the study show the importance of addressing mental health concerns in juvenile diversion programs where they are likely to lessen the mental health symptoms these youths experience. The findings of the study are further evidence for the need of mental health services in settings youths encounter prior to juvenile justice settings.

Jamie et al. (2017) also support increasing mental health screenings and services among incarcerated youth and those who are at risk for incarceration due to the findings of their study. The researchers examining the perceptions of recidivism among incarcerated youth determined whether mental health screening and service delivery reduced future interactions with the juvenile justice system. The findings revealed significant relationships between trauma incidents and mental health disturbances and that these trauma incidents were positively associated with 
perceived likelihood for future arrest and incarceration. The authors discuss the importance of early mental health services youths can receive to target the underlying trauma incidents and alter distorted cognitions. They explain that the great need for mental health services in juvenile justice systems comes from lack of knowledge on how to provide such services in a transition from punitive measures to a more rehabilitative philosophy (Jamie et al., 2017).

Consistent with these results, Burke and Dalmage (2016) found that the parole officers who work closely with youths in the juvenile justice system are often unfamiliar with the special education process as well as the educational and mental health needs these youths have. In addition to the clear need to provide education for the professionals who are currently working with at-risk youth in the community, there is also a need to turn to the individuals who demonstrate the risk factors for the school to prison pipeline themselves to determine their qualitative experiences of what services they hope to acquire and how they make sense of life experiences.

A qualitative study focused on how young offenders in the community make sense of life experiences such as transitions and instability and how this impacts coping behaviors shows the importance of taking a client-centered view into mental health treatment (Heath \& Priest, 2016). The results of the semi-structured interviews revealed that one main theme was defined by the ability for the youths to manage difficult experiences they face on a day-to-day basis. All four accounts suggested some type of avoidance or denial of affect; the youths also spoke about putting themselves in risky situations or using harmful behaviors (cutting, alcohol, drugs) as useful coping strategies. The youths discussed a lack of respect between themselves and the professionals they were currently working with due to the inability for the professionals to build a relationship with them before forming a hypothesis. Taking both the mental health needs of at- 
risk youth and the current lack of knowledge on how to address such needs into consideration, the review turns to current literature that is aiming to address the leading risk factors for the school to prison pipeline.

\section{Current Services Addressing the Risk Factors}

Over the last decade, as the school to prison pipeline became an increasingly more common route for at-risk youth, many communities and organizations created after-school care programs that targeted many different outcomes including lowering recidivism, increasing school attendance, lowering externalizing behaviors, increasing academic performance, and decreasing suspensions/expulsions (Farrington et al., 2017). While the proposed project intends to increase the services after-care programs provide in the community, results of studies examining after-care and re-entry programs provided to at-risk and incarcerated youth shows the potential for utilizing the programs as preventative measures. A meta-analytic review examining 22 independent studies aimed to gain insight on the effectiveness of after-care programs aiming to reduce recidivism among juvenile offenders (Farrington et al., 2017). The study found that the program had a small and positive effect on recidivism and that the program was most effective when it consisted of intensive individual treatment. Although the results only had a small positive effect, the authors emphasize the need to utilize after-care programs as a preventative measure prior to the youths' involvement with the juvenile justice system.

One quasi-experimental study aimed to analyze the results of an after-care program as a preventative measure for overall academic outcomes for at-risk youth living in the community. The prospective study was designed to compare school attendance, school suspension, and other academic outcomes among program participants (Jenson et al., 2018). The interventions included in the program were structured literacy and reading instruction; individual tutoring 
focused on increasing participants' reading, math, science, and social science skills; and social/emotional skill training groups. The results of the study showed that the youths who participated in the community-based after-care program had significantly higher rates of school attendance than young people in the comparison group. The participants also displayed significantly greater increases in reading skills over the academic school year and were significantly less likely to receive a suspension or expulsion from school. While the main focus of this particular program was academic performance, the results show the benefit of also having a social/emotional component in reducing overall suspensions and expulsions.

Contrary to the results of the 2018 study, a systematic review conducted in 2015 concluded that 24 after-care programs were found to have small and non-significant effects on externalizing behaviors and school attendance outcomes (Kremer et al., 2015). Regarding the interventions provided in each of programs, $12.5 \%$ of them were comprised on entirely academic components, $41.7 \%$ were a mix of academic and non-academic components, and $29.2 \%$ of them were all non-academic components. The mix in type of interventions provided could likely have a contributing factor to the non-significant results observed. The authors explain the need for future after-care programs to have strong well-defined theories of change and intervention procedures. Research has also found that after school program studies have poor utilization of treatment manuals and provide limited training and supervision for the individuals implementing the program. Due to the variability of implementation type for the studies included in this review, it is crucial to analyze the effects of after school programs that are currently targeting solely personal and social skills for at-risk youth.

Taylor et al. (2017) reported positive and significant findings when examining after-care programs that offered interventions that targeted personal and social growth. Outcomes were 
examined in three general areas: feelings and attitudes, indicators of behavioral adjustment, and school performance. The authors concluded that there were significant increases in youths' selfperceptions, bonding to school, positive social behaviors, school grades, and test scores within all of the included studies. Along with the increase in positive behaviors exhibited, there was also a decrease in problem behaviors for those involved in the study (Taylor et al., 2017). The meta-analysis strongly supports the use of community settings for promoting youths' personal and social well-being and begins to show the potential the field of occupational therapy could have in this setting.

\section{Potential of Occupational Therapy}

Occupational therapists around the country currently work with students in the school system who have special education disabilities. OT is the client-centered therapeutic use of everyday life activities (occupations) with individuals and groups that facilitate participation in roles, habits, and routines across all life settings (AOTA, 2020). Occupational therapists are educated to apply knowledge of mental and physical health with a focus on participation and the role of occupation to help clients promote health, prevent disability, and overcome or manage health challenges. Occupational therapy practitioners apply a distinct perspective through the use of performance-based assessments and an emphasis on and understanding of the relationship between occupational participation and health and well-being. In addition to supporting client skill development and adaptive responses, occupational therapists analyze the complex interplay among client variables, activity demands, and the environments and contexts in which activities take place, and they use their distinct skills to adapt or modify tasks or environments to support goal attainment and optimal engagement in occupation so that clients can develop and maintain healthy ways of living (Burson et al., 2017). Going beyond the school environment, occupational 
therapists have had limited opportunities to promote mental health with at-risk youth in other settings such as criminal justice settings and few after-school care programs; however, the results yield positive.

Mental health is defined as a state of well-being in which a person realizes his or her abilities, copes with challenges, and is able to work and contribute to the community (World Health Organization, 2013). Occupational therapists bring a perspective of rehabilitation to mental health services keeping a large emphasis on recovery and wellness directed toward independent participation in daily life occupations (Burson et al., 2017). Children with mental health deficits typically receive OT services in hospitals, community mental health treatment settings, private therapy clinics, domestic violence and homeless shelters, schools, day care centers, and other early education programs (Mahaffey, 2016). The overall goal for OT practitioners providing mental health services is to promote participation in occupations that are crucial for a healthy childhood and set the child up for success throughout their lifetime.

In a criminal justice setting in which OT has intervened, Munoz et al. (2016) took the perspectives of current occupational therapists working in this setting to determine the primary areas of occupation in which they work with clients. The occupational therapists report using many mental health models, frames of reference, and assessments when creating the foundation of treatment for the clients. The two primary areas of focused identified by the occupational therapists were interpersonal communication/social and problem-solving skills. The focus on mental health in this setting is appropriate due to the varying mental health conditions the individuals in this setting experience.

Although the foundation of OT is grounded in mental health, Cahill and Egan found that occupational therapists are disproportionately absent from mental health environments due to 
traditional mental health team members having a limited view of the role that occupational therapy has in mental health (Burson et al., 2017; Cahill \& Egan, 2017). Leadley and Hocking (2017) also support the use of an occupational perspective when working with at-risk youth and individuals who experience occupational deprivation. The authors explain that taking an occupational perspective may prompt consideration of the impact that being impoverished or disadvantaged has on the student's access to and performance of daily occupations (Leadley \& Hocking, 2017). The authors conclude the study by providing a future direction for the field of OT within mental health settings, specifically in the community. Few studies on the potential of OT in community settings contribute to the growing body of literature and continue to support the need for expansion to these settings.

\section{Occupational Therapy Support for At-Risk Youth}

\section{Quantitative Evidence}

Two studies on OT programs for at-risk youth in community settings highlight the importance and the benefit of occupation-based and mental health treatment to improve occupational engagement. Cahill et al. (2020) analyzed 62 studies that utilized activity and occupation-based interventions as support for mental health for at-risk youth. They found that the interventions that yielded moderate to strong evidence included yoga and sports. Moderate strength evidence supports the use of play and creative arts and evidence for the use of animalassisted interventions, meditation, video and computer games, and productive occupations was of low strength. The review highlights the importance of leisure occupations to support at-risk youths' overall mental health. The study results suggest that yoga can be used to address mental health, positive behavior, and social participation of all children and youth. 
The second study examined the use of play throughout the occupational therapy training program (OTTP) to acquire overall life skills (Shea \& Siu, 2016). The OTTP provides a weekly life skills group for inmates at the juvenile justice center in San Francisco and involves crafts, games, and interactive activities. Topics of group interventions included but were not limited to various life skills such as self-management, vocational exploration, and social/communication. The authors found that play itself can bolster a youth's sense of self-efficacy and reduce stress, especially at challenging moments. The study also found a link between the qualities related to playfulness (flexibility, intrinsic motivation, internal control, social competence, and adaptability to change) and coping skills, crucial for the mental health and development of at-risk youth. While these studies show the potential for OT domestically, international studies are another beneficial place to find evidence on the need for the profession working with at-risk youth.

One international study conducted in 2019 examined one-on-one semi-structured interviews with service providers serving the youth population in Hong Kong with the purpose of exploring how risks associated with disenfranchised youths are defined in Hong Kong and how these risks are addressed by the service providers (Chi-Kwan Shea et al., 2019). Of the 13 total services providers interviewed, four of these individuals included were occupational therapists. After analyzing the data, two major subthemes emerged: behavioral risks and underlying personal, environmental, and contextual factors experienced by the youths, and primary aspects of services provided to the at-risk youth population.

Under the first theme, four subthemes also emerged: illegal drug use and abuse, academic disengagement, engagement in other unhealthy occupations, and unsafe sexual practices. The researchers found that at-risk youths often engage in unhealthy occupations when they are bored with their current life situation and feel as though they have no direction in life. They conclude 
that by providing intervention for at-risk youth in the community and by offering alternatives to their unhealthy lifestyle, they can find new engagement in novel occupations and begin to form an idea of what they want out of life. The program provided organized football clubs, basketball teams, and online gaming competitions in hopes to offering alterative leisure occupations. Using education as an intervention, the program also employed daily chores and opportunities to develop nonacademic passions and skills. The results of this study show the importance for aftercare programs to focus not only on academic performance, but also on implementing opportunities for leisure engagement and employment exploration.

The second international study took place at Ban Mutita Juvenile Vocational Training Center for Boys in Thailand (Khemthong, 2017). Thirty-one boys at the facility were recruited into an OT program using selective sampling under a cut-off score of volitional and vocational assessment. The study hoped to improve the acquisition of volitional and vocational skills through activity and occupation-based interventions. Activities completed in the program included making their friends name tags, drawing a picture of the future, and threading their own bead patterns. The results showed that the participants' volitional and vocational scores significantly improved after they had engaged in the 4-week OT program in combination with the existing study programs. The study shows the overall impact the OT programs, which focused on the open system of making choices, developing motivation, learning new skills, breaking routine, and building rapport, can have on young offenders with low volitional and vocational skills. The quantitative data provided by the domestic and international occupational therapy programs for at-risk youth are crucial to visualize the potential benefits of the profession; however, qualitative data based on the youths' experiences in these programs are just as important to understanding the benefit of occupational therapy's unique client-centered role. 


\section{Qualitative Evidence}

One qualitative study analyzed the effects of a summer camp experience on factors of resilience in at-risk youth (Merryman et al., 2012). The 5-week camp served as an extension of an after-care program that was already in place. The occupation-based groups addressed psychosocial skills through developing a personal webpage, exploring career interests, engaging in self-regulating craft activities, preparing healthy snacks, and completing a 5-session peer pressure module. After conducting interviews with the youths engaged in the camp, three themes emerged: engagement influenced skill competence, camp environment expanded positive choice and availability of positive occupations, and males developed skills and resilience from information neighborhood physical activity while no equivalent existed for females. The study results suggest that at-risk youth can develop skills of positive identity, social skills, physical and thinking skills, and positive values through an occupation-based approach that provides an enriched, structured camp experience designed to increase skills through occupational engagement.

The OTTP is another example of a community-based organization that serves at-risk youth and that targets the occupations of schooling, social participation, play and leisure, and employment (Shea \& Jackson, 2015). The qualitative study shows the strongest evidence on the need for client-centered occupation-based treatment for at-risk youth in the community. The researchers sought the perspectives of young people in the program. Three main themes emerged: client-centered and occupation-based intervention process, youths increased selfadvocacy, and the youths' enhanced perception of their future.

Client-Centered and Occupation-Based Intervention Process. The clients viewed the experiences as reflecting a culture of mutual respect and regard. They felt as though OT gave 
them options and allowed them to engage in things they wanted to do rather than being told what to do. They felt this way as a result of using a client-centered approach to therapy. This approach allows an OT practitioner to gather information to understand what is currently important and meaningful to the client and to identify past experiences and interests that may assist in the understanding of current issues and problems (AOTA, 2002). After determining the interests of the youth, preparatory activities such as verbal expression of personal interests and strengths, assertive communication, and self-management were used to increase self-awareness and practice essential life skills. Mindfulness activities were also used to increase emotional management skills and reportedly helped the participants feel more in control of their problems. Interventions focused on advocacy empowered the youths to obtain access to community resources by connecting them to their schools and other agency-based services including youth employment and internships, completing resumes, and accessing general education development tutoring clinics (Shea \& Jackson, 2015).

Youth's Increased Self-Advocacy. One verbally expressed personal interest of the youth was the ability to self-advocate. Following the program, the youths each discussed at least one situation per participant in which they were able to assertively confront an authority figure, such as a teacher, parent, or employer, to get a desired outcome. They were able to articulate the situation and fully explain themselves in an assertive way, without being rude, aggressive, or yelling. While building on communication skills, the youths also had the opportunity to reflect on weaknesses within themselves that impeded their ability to practice effective communication. For some, this was due to being shy and reserved while for others it was the fear of looking stupid and having no self-confidence (Shea \& Jackson, 2015). 
Youth's Enhanced Perception of the Future. Perceptions of the future were also addressed as each youth, despite their at-risk status, was able to fully articulate a future plan and describe skills that would help them carry out these individual plans. Participants who were resistant at the start of the program found themselves finding the value in employment and independent living skills in order to live fully independent in the future. Other participants had a goal of financial management skills and financial stability as a prerequisite to attending a local community college. The researchers conclude that youth who have a positive perception of the future are more likely to assert increased effort into building that future. OT, specifically within this setting, promotes the acquisition of life skills through occupation and collaborative relationships (Shea \& Jackson, 2015).

\section{Mental Health Defined for the Project's Program}

The proposed mental health 9-week program developed to increase the amount of services provided to at-risk youth in the after-care setting is developed and grounded in occupation. The main occupation that the session objectives and activities will bolster is education. OT's contribution to the field of mental health utilizes occupations the clients need and want to do and examine variables that influence their performance in everyday life (Burson et al., 2017). The program, through the use of activities, will promote mental health and support participation in the occupation of education for at-risk youth. The promotion of mental health, which is understood as a state of well-being in which a person realizes his or her abilities, copes with challenges, and is able to work and contribute to the community (World Health Organization, 2013), will remain the focus of all sessions and activities.

Recognizing emotions, the first session topic, is imperative to promoting the mental health of at-risk youth. Emotion regulation, defined as actions or behaviors a client uses to 
identify, manage, and express feelings while engaging in activities or interacting with others, is identified as a performance skill in the Occupational Therapy Practice Framework (OTPF) and begins with emotional awareness (Brown et al., 2019). In order to effectively regulate emotions, the client must be aware of the emotions they feel in order to further honor the experience and change their perception on future events that may bring up these emotions. Individuals who are sensitive to emotional experience, such as the at-risk population, may suppress or subdue their emotions leading to maladaptive behaviors over time. This session ties back to the occupation of education by enhancing the youths' performance at school through the development of emotional awareness.

The second session topic, calming sensory strategies for test taking, uses mindfulness techniques to impact the youths' ability to regulate emotions through the introduction of the zones of regulation. The intervention is designed to assist individuals in developing selfregulation skills and helps youths identify their level of arousal using four categories or zones that move from low alertness to hyperarousal (Brown et al., 2019). The students will be able to identify the emotions that belong in each zone while determine ways to cope with each zone. The session will be grounded in occupation by encouraging the youths to determine ways in which the coping strategies or mindfulness techniques can be used before, during, or after taking a test a school.

Organization and time management, the topic of the third session, is important in promotion mental health and well-being for at-risk youth by encouraging development of lifestyle balance (Brown et al., 2019). Compared with the general population, individuals with mental illness spend less time in productivity or active leisure activities and more time sleeping and in passive leisure. It is important to educate youths on the importance of developing healthy 
habits and routines as well as satisfying pattern of daily occupations that is healthy, meaningful, and sustainable to the individual. In terms of education, at-risk youth must be able to balance school, after-care, home, personal, and social life.

Sessions four and five and eight address recognizing/managing aggression and conflict resolution, two important topics needed to navigate the school environment effectively. Anger is known to be one of the most common and problematic disturbances associated with emotion dysregulation (Brown et al., 2019). Sessions addressing these topics are needed to promote the mental health of this population through education on emotional awareness, problem-solving, relaxation, and communication. These skills will assist the youths in the occupation of education by providing strategies for dealing with such emotions or situations in the school environment.

Building self-esteem through promotion of personal and friendship traits, the topics of sessions six and seven, promote at-risk youth mental health by improving personal resilience and the ability to cope. Research shows that a child's self-esteem directly affects personal resilience and the ability to cope (Brown et al., 2019) and a key area of importance in the perceptions children have of themselves is the development of friendships. Through recognition of their individual traits and as well as traits in positive friendships, the youths will be better equipped to handle the personal and social aspects of the school environment. The final session of the program, bullying and cyberbullying prevention, also aims to develop and improve crucial skills to building and maintaining positive friendships in the school environment.

Overall, the program aims to increase the amount of services promoting mental health to at-risk youth in the after-care setting. Session topics promote the mental health of at-risk youth through a focus on developing emotional awareness, emotional regulation, mindfulness techniques, lifestyle balance, effective communication, and strategies for building and 
maintaining positive friendships. The session activities will support participation in the occupation of education by assisting the youths in developing strategies to better navigate the school environment. While the session topics were informed by information published through AOTA and the Journal of Occupational Therapy, the program population, setting, and activities were developed with theoretical support from occupation-based models.

\section{Theoretical Support}

Occupation-based models serve as overarching or umbrella theories the profession uses to explain the relationship of occupation, person, and environment (Cole \& Tufano, 2008). The models do not focus on any specific age or disability but rather apply to all of them. Occupationbased models guide OT practitioners when selecting evaluations and assessments for a particular group or practice area. The models can be used independently, in conjunction with other models, or in conjunction with frames of reference. While models provide overarching guidance, frames of reference provide more specific guidance on intervention for a specific age or disability. The proposed project will utilize both the Person-Environment-Occupation-Performance (PEOP) and Ecology of Human Performance (EHP) models to focus on each individual client's needs and interests as well as taking a broader perspective to accommodate the needs of the host facilities.

The PEOP model focuses on what the person wants or needs to do (occupation), how they are currently doing in the occupation (performance), intrinsic characteristics (person), and extrinsic characteristic (environment) (Baum \& Christiansen, 2005). PEOP examines interdependent components that contribute to occupational performance among individuals and families, organizations and groups, and populations and communities. The central focus of this model is how the person-environment-occupation-performance interaction and its related factors contribute to successful occupational performance. The main therapeutic outcomes for the PEOP 
model include participation, occupational role performance, identity and realization of self, life satisfaction, happiness, and well-being. An occupational therapist working with this model understands that every person has an innate desire to master their environment and takes in many psychological factors on performance to promote a person's best functioning level.

The PEOP model will be useful in this setting to guide intervention at the person and environment level to influence the occupation and performance level. The top-down nature of the model will ensure that the overarching occupation of education will remain central to all sessions and activities provided to at-risk youth. The model has been used with children in the past that show the effectiveness of PEOP-guided interventions and has potential to be expanded in this setting. Strong et al. (1999) compiled various case studies in their analysis to show the different aspect of application of the model in which one was a 9-year-old child receiving school-based services. In 2008, Payne provided a description of how to apply this model for children with developmental coordination disorder. The proposed project intends to utilize the PEOP model to find similar finding of effectiveness with this population.

The EHP model focuses more on the role of context or environment in overall task performance (Dunn et al., 1994). A strong focus on context allows OT practitioners to consider how features from the environment influence a person's engagement in task performance. The EHP model has four main components that define its practical use and include person (sensorimotor, cognitive, and psychosocial domains), task (set of behaviors necessary to accomplish a goal), context (temporal and environmental aspects), and performance (personcontext-task transaction). Function in this model is indicated by a person's ability to participate in numerous occupations and roles that match their personal preferences and capacities and the 
demands of the environment successfully. Restriction in performance range is evident when a disruption occurs in the transaction among the person, the context, and the tasks.

The EHP model was used in the development of the purpose, rationale, and significance of the proposed project. By analyzing the target setting and population through the cultural, physical, temporal, and social aspects, the project was able to define the objectives which serve as the foundation of the program. In this model, motivation is elicited by directly asking a person what they want and need. By gaining program feedback from the youth, the project will gain more insight prior to making modifications to future sessions. Overall, the project will show the need for skilled OT within these settings to bring a client-centered and occupation-based approach to overcoming barriers and facilitating engagement in traditional childhood roles and occupations.

\section{Conclusion}

Poverty, family dysfunction, violence, trauma, academic problems, mental health difficulties, and unstable neighborhoods in urban areas are among the leading risk factors for entry into the school to prison pipeline (Mallett, 2017). While after-care programs target social participation and education, there is a lack of client-centered and occupation-based interventions (Shea \& Jackson, 2015). These interventions, including a focus on mental health, would enable at-risk youth to advocate for themselves, gain meaningful occupational experiences, and increase overall occupational engagement. Unfortunately, the interventions provided through after-care programs often overlook the benefits of social and personal growth. Therefore, many studies attempting to determine the personal and social benefits of such after school programs have had inconsistent findings (Weissberg, 2019). 
The proposed program development project intends to address the problem of the lack of therapeutic services in after-care settings by developing and integrating a group mental health program into the curriculum at two Florida after-care facilities. The program will be provided weekly for 1 hour and each session will address a different mental health topic informed by the AOTA school mental health toolkit as well as collaboration with facility staff. Following the termination of the program, the staff will be provided with a program portfolio that they may use in the future to implement the mental health group session into the curriculum. Overall, the project aims to increase mental health services in after-care settings to lower the number of atrisk youth entering the school to prison pipeline. 


\section{Chapter III: Project Description}

As the number of school-aged students caught in the school to prison pipeline continues to rise as a result of zero-tolerance policies across school districts in disproportionately low income and minority neighborhoods, many settings that serve these very students lack supporting services that promote the development of skills necessary to achieve adequate mental health (Tokolahi et al., 2016; Shea \& Jackson, 2019). The proposed project serves the purpose of closing the gap of the lack of services in after-care settings by creating, performing, and analyzing the effectiveness of mental health group sessions run with groups of middle school students who are identified as at-risk. The project identified a need for mental health services at two Jacksonville after-care centers which serve school-aged students from elementary to high school.

The proposed project intends to run mental health group sessions using Cole's Seven Step Model with participant groups of 10-20 middle school students once a week for 9 weeks. The group session topics will be based on the needs assessment with the facility, the current literature on mental health treatment for at-risk youth, and information published from AOTA on pediatric mental health promotion. The potential outcomes of this project include building critical skills to engage in age appropriate roles and occupations for at-risk youth, increasing services and interest for and of students at the host facility, adding an emerging practice area for the field of occupational therapy (OT), and lowering the number of students caught in the school to prison pipeline for the local community overall.

The proposed project has numerous objectives that will serve as a foundation for the goals of the project and assist the project in developing group sessions and include the following: Learning Objectives: 
- Compare and contrast the demographics of youth at the host facilities with the current literature

- Compare and contrast services provided to at-risk youth at two after-care centers

- Compare and contrast services provided to at-risk youth in the after-care setting to other settings that serve this population

- Assess relevance of group topics to students at host facilities

- Apply understanding of staff trainings for child abuse and mandated reporting in sessions Outcome Objectives:

- Implement group sessions targeting mental health to youth at host facilities

- Educate youth on recognizing and coping with positive and negative emotions

- Educate youth on appropriate social and relationship building skills

- Promote youths' self-confidence and personal strength identification

- Promote academic achievement through the development of necessary life skills

- Acquire and review program feedback on group session effectiveness, level of interest, and future suggestions from at-risk youth

\section{Process and Methods}

\section{Participants}

The project participants will consist of participant groups of 10 middle school students identified as at-risk in low-income areas in Jacksonville, Florida. Analyzing the demographics of students at MaliVai Washington Youth Foundation (MWYF), 39\% are currently living below the poverty line and $1 / 3$ have a parent who is incarcerated. At the DuPont YMCA, $>80 \%$ of the students belong to minority groups and all schools they serve are on free or reduced lunch. The middle school students participating in the group sessions will range from $6^{\text {th }}-8^{\text {th }}$ grade and will 
range from ages 10-14. Participation in the project will be voluntary and may be accompanied by 1 staff member. Post-session reflections will be completed after sessions to assess effectiveness and level of interest in group sessions.

\section{Setting and Measures}

The proposed project will take place at two after-care centers in Jacksonville, Florida. The first, MaliVai Washington Youth Foundation (MWYF), currently hosts 200 students from multiple different schools in Duval County and has 3 split programs based on age and grade level for elementary, middle, and high school students. The programs have a daily homework hour, tennis hour $2 \mathrm{x}$ a week, a mentoring program, and optional tutoring, leadership, and one-on-one mental health treatment. The facility needs include building upon the leadership portion of the program to include a preventive mental health session the youth can engage in to maintain interest and build upon crucial developmental skills promoting mental health.

The second facility, DuPont YMCA, currently hosts 25 students due to COVID-19 restrictions that serves 6 different schools in the area. The program is split based on age with half of the students being kindergarten to $2^{\text {nd }}$ grade, and half being $3^{\text {rd }}$ grade and up. The program starts off with a physical activity followed by dinner, homework time, and alternating activities. The facility need is an introduction of mental health topic education to youths to improve their overall social and academic performance in and out of school.

Each week, the participating students will complete a post-session reflection that covers program feedback on the effectiveness of the session, the level of interest in each session, and suggestions for future sessions. The questionnaires serve as a method for enhancing and continuously reevaluating the effectiveness of the sessions based on the youth's perception. The sessions will be tailored to the interest of the students to maintain engagement as well as build 
upon the goals of the project. The reflections will also be analyzed to determine the effectiveness of each session topic and level of interest to disseminate and potentially influence other aftercare programs to implement such sessions.

\section{Development process}

The proposed project was created via an exploration on topic interest and a literature search on mental health services that are currently being provided to at-risk youth in and out of school. The research revealed a gap in the literature and indicated that after-care programs often provide the necessary academic assistance to students after the school day has ended; however, neglected to provide other services including mental health promotion (Jenson et al., 2018). The gap in the literature will be addressed by the program development type project through the development, implementation, and analysis of mental health group sessions with middle school students at MWYF and the DuPont YMCA.

The project idea was also developed through collaboration with the project mentor and the staff at MWYF and the DuPont YMCA. Multiple staff members at both facilities provided their insight on what the facility is already doing, what they should be doing, and what they could be doing with the help of the project. Titles of the staff members involved include the teen center director, community outreach manager, and program director. These staff members and the project mentor will continuously provide feedback on session topics and content to ensure accuracy and success of the sessions.

The program feedback for the project will be obtained from the middle school students participating. Students will attend all group sessions, engage in all activities, and complete postsession reflections after each session. The group of students will be decided by the MWYF and YMCA staff based on population need and availability. 


\section{Implementation process}

The project will be completed over 14 weeks and will include time developing relationships with students and staff, working with students and staff, attending and participating in leadership camps, collecting program reflections from students, developing group session objectives and activities, and debriefing at the termination of the project. Outside the weekly 1 hour group sessions, the project will observe other courses and activities, provide recommendations when appropriate, and participate in staff meetings to contribute ideas and remain up to date in facility policies and announcements.

The mental health group sessions will occur weekly for one hour for 9 weeks with each session covering and promoting a different mental health topic with structure from Cole's Seven Step model. Each week in the project, a specific objective, influenced by the AOTA school mental health toolkit, will be covered (American Occupational Therapy Association [AOTA], 2015). The model will provide structure and organization while the toolkit provides content and accuracy. Weeks 10-14 of the project will be spent analyzing the information gathered in the post-session reflections and conducting the final debriefing session with staff and students.

The program feedback from the implemented sessions will be taken from the students in the form of reflections that will provide the project with feedback and direction. The first part of the reflection will determine if the students enjoyed the sessions and to what extent they enjoyed the session. The second part of the reflection will determine if the students believed the session accomplished the goals set out for that day. The last part of the reflection will allow the students to provide suggestions for future sessions to improve the context and engaging nature of the sessions. Refer to appendix B for an example weekly reflection form.

\section{Evaluation component}


Following the termination of the project, staff members and students will be debriefed regarding the overall success and perception of the project. Students and stuff will have the opportunity to reflect back on the entirety of the project and add any appropriate verbal feedback.

This session will occur during the last week of the project and provide a more informal format for feedback and open discussion.

\section{Conceptual Framework}

Figure 1

Logic Model

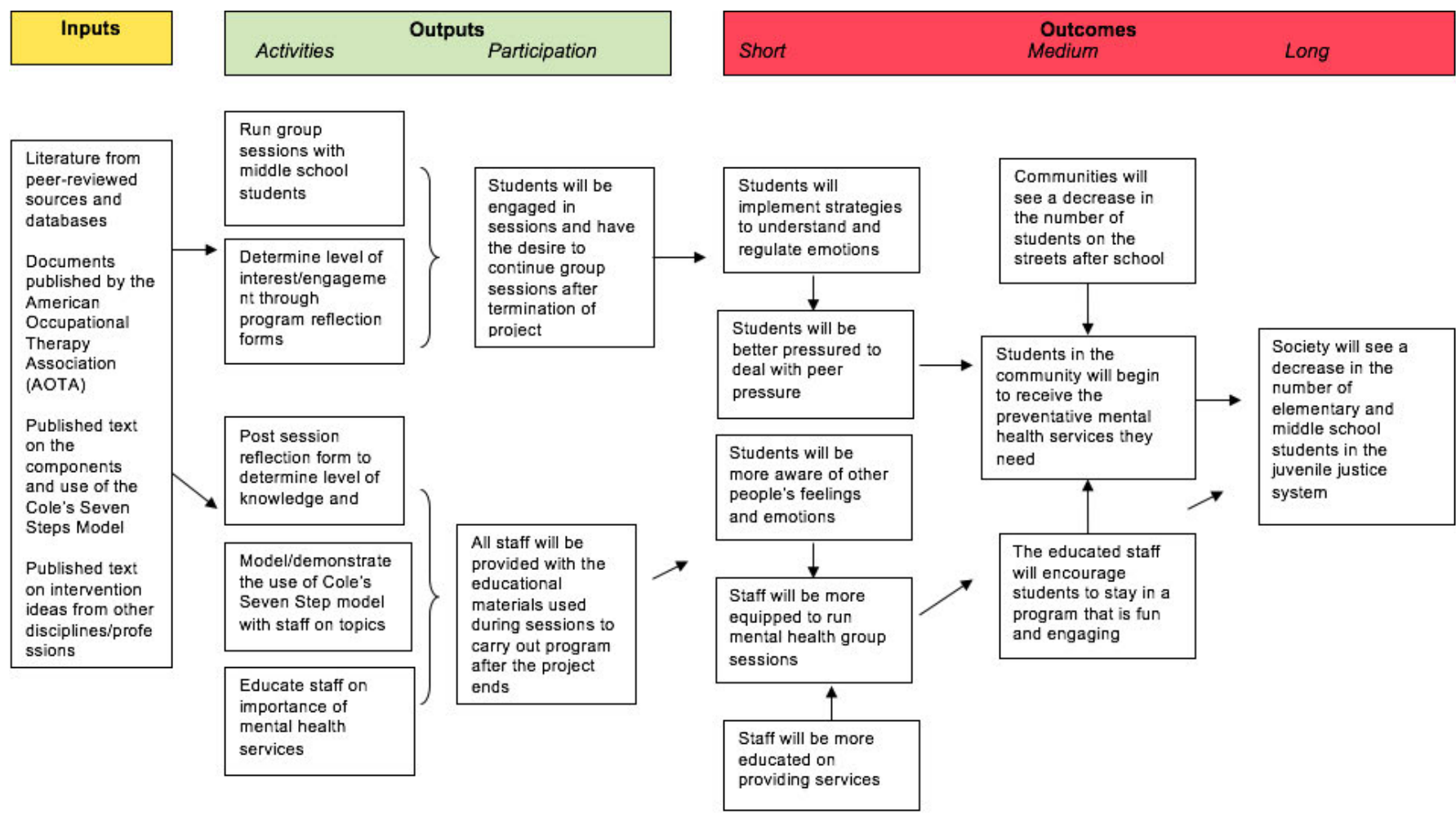

\section{Timeline}

\section{Needs assessment}

A needs assessment of the population and setting was completed first to determine the gap in the literature. After determining the gap as a lack of supporting services in after-care settings for at-risk youth, a needs assessment for two Jacksonville after-care facilities was 
completed to determine a need for a focus on mental health promotion for middle school students. The project will begin by attending a leadership camp in which relationships can begin to form with both the staff and students at MWYF. Once the project continues on in January, observations will take place every week at MWYF and YMCA to ensure the needs assessment is completed in a cyclical process rather than on one occasion. Attending staff meetings throughout the 14 weeks will also ensure that the needs of the staff and students are being consistently updated and considered.

\section{Implementation of Group Sessions}

Weeks 1 through 9 will be dedicated to creating and completing mental health group sessions with a differing topic each week. Week 1 will cover recognizing emotions, weeks 2 will cover calming sensory strategies for test taking, week 3 will cover organization and time management, week 4 will apply these skills to studying, week 5 will cover recognizing/managing aggression and conflict resolution, and week 6 will build confidence and self-esteem through promotion of personal traits. For the latter half of the project, week 7 will cover identifying positive traits in friendships, week 8 will promote positive communication with authority figures and adults, and week 9 will cover strategies for what students can do to prevent bullying and what to do if they are bullied. The last 5 weeks of the project will be spent observing sessions at each facility, providing feedback and suggestions where appropriate, and attending any camps and/or staff meetings. Refer to table 1 for a visual breakdown of how each session will meet the objective goals for each week of the project.

\section{Table 1}

Projected Program Timeline 


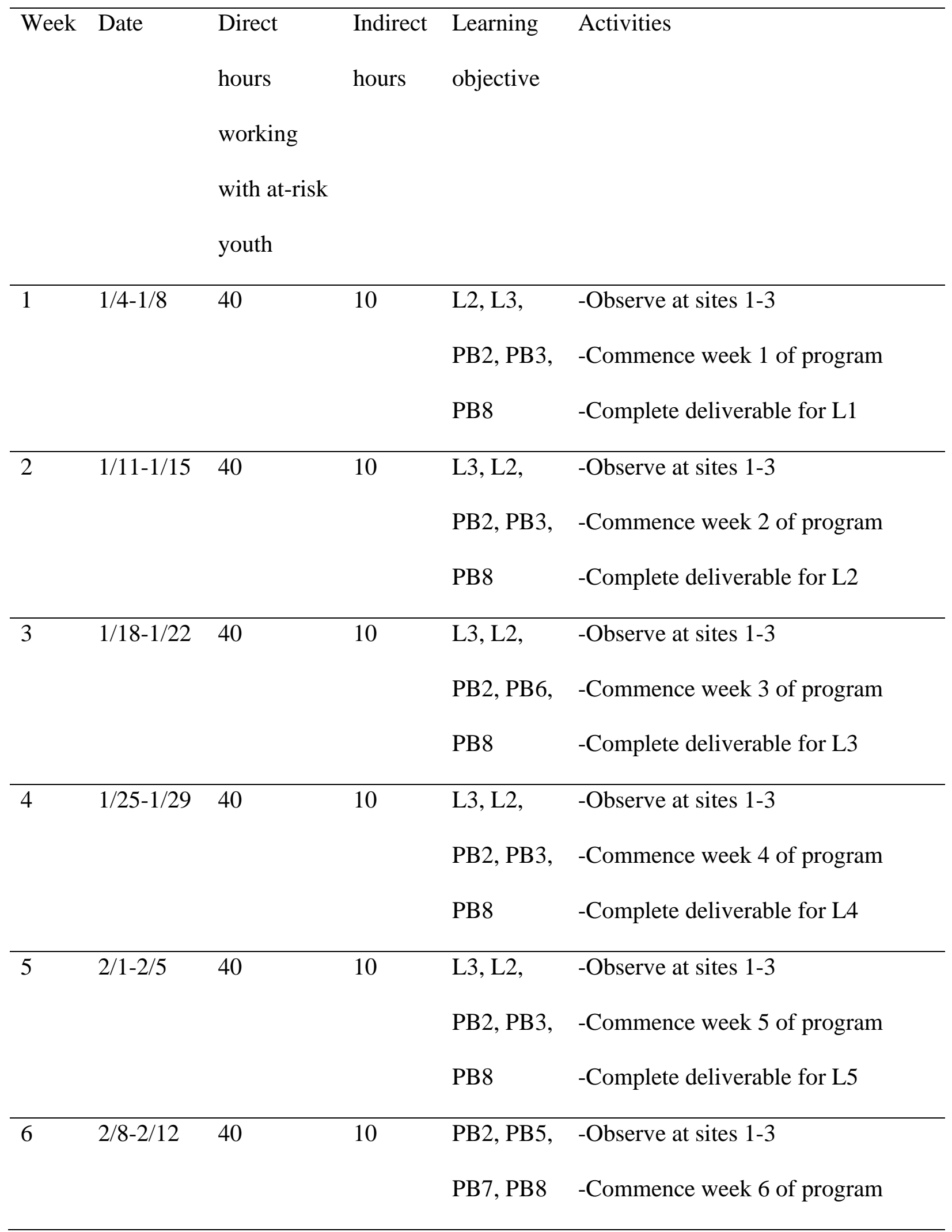




\begin{tabular}{|c|c|c|c|c|c|}
\hline 7 & $2 / 15-2 / 19$ & 40 & 10 & $\begin{array}{l}\text { PB2, PB4, } \\
\text { PB7, PB8 }\end{array}$ & $\begin{array}{l}\text {-Observe at sites 1-3 } \\
\text {-Commence week } 7 \text { of program }\end{array}$ \\
\hline 8 & $2 / 22-2 / 27$ & 40 & 10 & $\begin{array}{l}\text { PB2, PB4, } \\
\text { PB7, PB8 }\end{array}$ & $\begin{array}{l}\text {-Observe at sites 1-3 } \\
\text {-Commence week } 8 \text { of program }\end{array}$ \\
\hline 9 & $3 / 1-3 / 5$ & 40 & 10 & $\begin{array}{l}\text { PB2, PB4, } \\
\text { PB7, PB8 }\end{array}$ & $\begin{array}{l}\text {-Observe at sites 1-3 } \\
\text {-Commence week } 9 \text { of program }\end{array}$ \\
\hline 10 & $3 / 8-3 / 12$ & 40 & 10 & & -Observe at sites $1-3$ \\
\hline 11 & $3 / 15-3 / 19$ & 40 & 10 & & -Observe at sites 1-3 \\
\hline 12 & $3 / 22-3 / 26$ & 40 & 10 & PB10 & $\begin{array}{l}\text {-Observe at sites } 1 \& 2 \\
\text {-Observe at site } 3 \\
\text {-Write chapters } 4 \& 5\end{array}$ \\
\hline 13 & $3 / 29-4 / 2$ & 40 & 10 & $\begin{array}{l}\text { PB10, } \\
\text { PB9 }\end{array}$ & $\begin{array}{l}\text {-Final observations at sites } 1 \& 2 \\
\text {-Observe at site } 3 \\
\text {-Write chapters } 4 \& 5 \\
\text {-Provide program manual to sites } \\
\text {-Create poster for dissemination }\end{array}$ \\
\hline 14 & $4 / 5-4 / 9$ & 40 & 10 & $\begin{array}{l}\text { PB9, } \\
\text { PB10, } \\
\text { PB11, } \\
\text { PB12 }\end{array}$ & $\begin{array}{l}\text {-Final observations at site } 3 \\
\text {-Write chapters } 4 \& 5 \\
\text {-Create poster for dissemination } \\
\text {-Submit completed and approved } \\
\text { project into SOAR }\end{array}$ \\
\hline
\end{tabular}


-Prepare completed work for

submission into journal

560

140

\section{Analyze Effectiveness and Success of Sessions}

Program feedback will be completed weeks 1 through 9 through reflections filled out by each student after sessions. Information will be analyzed each week to take suggestions for future sessions and interest level into account and adjust accordingly. Final informal feedback will also be taken during the debriefing session during the last week of the project.

\section{Evaluation of Questionnaires}

At the end of the 9 weeks, the information gathered from the students will have provided program feedback on the overall effectiveness of each session covered in the project. The results of the feedback forms will provide insight into the effectiveness of future mental health group programs run with at-risk youth in an after-care setting.

\section{Conclusion and Next Steps}

The current literature on the topic of the school to prison pipeline shows the need for increasing preventative mental health services to at-risk youth in school and out of school. The use of Cole's Seven Step model to create and structure mental health group sessions allows for a focus on occupation to be prominent while also encouraging participation and social interaction with peers (Cole, 2018). Occupational therapy mental health treatment has shown promising results in reducing problem behaviors and increasing occupational performance (Cahill et al., 2020; Shea \& Siu, 2016; Tokolahi et al., 2016). At the termination of the project, the intention is that the participants will feel as though they learned crucial skills needed to better navigate the 
school environment and make the right choices regarding behavior. If the project shows significant results, this project could be a foundation for future researching aiming to increase preventative mental health services for at-risk youth in after-care settings across the country. 


\section{Chapter IV: Results and Analysis}

Society today faces the problem of having a lack of supporting services addressing mental health and occupational performance provided to at-risk youth in after-care settings. The purpose of the program development type project was to increase the supportive mental health services provided to at-risk youth in the after-care setting. The progress of the program development type project is dependent on completion of both learning and program-based objectives which serve as a means and an end to the success of the project. In this chapter, all learning and program-based objectives will be explained with their corresponding results and analyses.

The learning objectives include comparing the demographics of youth at the host facilities with the current literature, comparing services provided to at-risk youth at two aftercare centers, comparing the services provided to at-risk youth in the after-care setting to other settings that serve this population, assessing the relevance of group topics to demographics at host facilities, and applying understanding of staff trainings for child abuse and mandated reporting in program sessions. The program-based objectives for the project include implementing group sessions targeting mental health to youth at host facilities, educating youth on recognize and coping with positive and negative emotions, educating youth on appropriate social and relationship building skills, promoting youths' self-confidence and personal strength identification, promoting academic achievement through the development of necessary life skills, and acquiring and reviewing program feedback on group session effectiveness, level of interest, and future suggestions from at-risk youth. The upcoming results and analysis section details the outcomes and progress made towards all learning and program-based objectives for completion of the capstone project and experience. 


\section{Project Summary}

The program development type project began with a needs assessment of both the population and setting to determine the gap in the literature that existed. After further defining the project's purpose to serve as a means of increasing supportive services in after-care settings for at-risk youth, secondary needs assessments took place at the two after-care centers in Jacksonville, Florida that would host the project. The needs assessment allowed the project to further define its goals of increasing the mental health supportive services targeting education on positive and negative emotions, appropriate social and relationship building skills, selfconfidence, and the development of necessary life skills for academic achievement. The first week of the project consisted of staff orientation meetings, online trainings, and communication with all staff members to prepare for the start of the project's 9-week mental health program.

Weeks 2-11 consisted of the 9-week mental health program that took place once a week for 1 hour at the two Jacksonville after-care center locations. Week 2 covered recognizing emotions, weeks 3 covered calming sensory strategies for test taking, week 4 covered organization and time management, week 5 applied these skills to studying, week 6 covered recognizing/managing aggression and conflict resolution, and week 7 built confidence and selfesteem through promotion of personal traits. For the latter half of the project, week 8 covered identifying positive traits in friendships, week 9 promoted positive communication with authority figures and adults, and week 11 covered strategies for what students can do to prevent bullying and what to do if they are bullied. Week 10 did not consist of a program session due to the student being out of school for spring break. Weeks 12-14 of the project was devoted to completing final observations with the population of at-risk youth and assisting the staff with courses when necessary. 
The participant groups for the program consisted of 10 middle school students on the roster; however, this number changed frequently throughout the duration of the program. Due to the variability to which students attend and miss school, the number of students in attendance per week ranged from 1 student to 8 students. The students were selected through the needs assessments with both facilities in which staff chose the specific class the program would be run with. At MaliVai Washington Youth Foundation (MWYF), the chosen students were the 'SOS' class which contained students that were placed there due to their low academic performance and achievement. At the DuPont YMCA, the chosen students were the group that stayed in the middle school building during the hours of the program. The program sessions took place on Wednesday at MWYF from 3:30 - 4:30 pm for the boys and 4:30 - 5:30 pm for the girls and Thursday at YMCA from $4-5$ pm for both boys and girls.

The plan previously described in the project description chapter outlined the number and age of the students that would be participating in the program; however, a few discrepancies were met along the way that likely influenced the results shown. While all students that participated in the program at MWYF were in fact middle school aged, the students at YMCA were often a mix of elementary and middle school aged students. The discrepancies seen in age could have impacted both engagement and understanding of all session topics and activities. The defined number of participants shifting from 10 to between 1 and 8 could also impact the results of the sessions as the averages for the post-session program feedback forms were based on varying number per week. While there were few discrepancies in the planning of the project, the population closely resembled demographics to that of the current literature on at-risk youth, showing the relevance of the program for future use with this population. 
According to the current literature on the population of at-risk youth who enter the school to prison pipeline, the demographics point to living in poverty, family dysfunction, violence, trauma, academic and learning problems, mental health difficulties, and unstable and disorganized urban neighborhoods (Mallet, 2017). When comparing these demographics to that of the students at both host facilities for the project, many similarities and differences are noted. At MWYF, 1/3 of the students have a parent who is or was incarcerated, showing the representation of students who fall victim to family dysfunction. A good portion, 20\%, of the students are also identified as needing individualized mental health services as determined by the psychologist on site, showing the representation of student who show mental health difficulties. At YMCA, a high percentage of children currently live in a single parent household and all of the schools they serve are on free or reduced lunch, showing the representation of students living in poverty.

The similarities of the demographics of the project's participants compared to the youths represented in the literature show the relevance of the project for the population of at-risk youth; however, differences must be acknowledged as well. Other factors for involvement in the school to prison pipeline consist of violence, trauma, academic and learning problems, and unstable and disorganized urban neighborhoods (Mallet, 2017). While many students at both facilities may have experienced these factors at any given time, there is no way for the project to objectively determine the rate and frequency at which these factors have influenced the lives of the students participating in the program. Due to complex and private nature of this information, the project assumes that these are differences of that compared to the at-risk youth described in the literature. While the demographics of the youths participating in the program did not change over 
the course of the project, organizational and personal conditions did influence the participants throughout the course of the program.

Organizational and personal conditions that occurred throughout the program had an influence on the information being delivered, the number of participants per session, and the program feedback obtained following each session. One organizational condition that took place was the preparation for bad weather in the local area. As an after-care center, MWYF is required to shut down services and request for all parents to pick up their children if the city of Jacksonville indicated this as necessary. During session 3 of the program, the city of Jacksonville experienced a tornado warning which caused the session with the boys to consist of 2 participants and the session with the girls to consist of 0 participants, as it did not take place. One personal condition that impacted the program was the contraction of the COVID-19 pandemic sickness among a few of the students. The sickness was easily traced to a few students who were required to stay home and miss the program sessions for 2 weeks. While impacting the number of participants per session, these conditions also impacted the delivery of the information in that session as well as the program feedback received.

The program was challenged with organizational and personal conditions; however, all objectives were followed and met with a specific outcome. Refer to table 1 for the project objectives and their corresponding outcome.

\section{Table 1}

Project Objectives and Corresponding Outcomes

Objective Outcomes


L1: Compare and contrast the demographics Comparison chart

of youth at the host facilities with the current

literature

L2: Compare and contrast services provided Comparison chart

to at-risk youth at two after-care centers

\section{L3: Compare and contrast services provided Comparison chart}

to at-risk youth in the after-care setting to

other settings that serve this population

L4: Assess relevance of group topics to Session feedback data chart on interest students at host facilities

L5: Apply understanding of staff trainings for Training certificate child abuse and mandated reporting in sessions

PB1: Implement group sessions targeting Program session manual mental health to youth at host facilities PB2: Educate youth on recognizing and Session $1,4,5$, feedback data chart on coping with positive and negative emotions effectiveness PB3: Educate youth on appropriate social and Session 7, 8, 9 feedback data chart on relationship building skills effectiveness PB4: Promote youths's self-confidence and Session 6 feedback data chart on effectiveness personal strength identification PB5: Promote academic achievement through Session 2, 3 feedback data chart on the development of necessary life skills effectiveness 
PB6: Acquire and review program feedback Data on full program feedback forms on group session effectiveness, level of interest, and future suggestions from at-risk youth

\section{Project Outcomes}

The project's program was developed for the purpose of increasing the supportive mental health services provided to at-risk youth in the after-care setting. The program aimed to address the problem of the lack of supporting services addressing mental health and occupational performance provided to this population in this setting. The project filled the gap of lack of services in after-care settings by developing, evaluating, and disseminating a program that addressed the mental health needs of at-risk youth in this setting. Youths were given the opportunity to build crucial skills and boost their overall self-esteem and self-efficacy to approach the school environment with new strategies and perspectives. The program results show the potential OT can have on increasing the mental wellness and occupational performance of at-risk youth.

\section{Learning Objective 1}

Regarding project goals, each was approached and achieved in a different way to influence the final outcome and results of the program. The first learning objective for the project was to compare the demographics of youth at the host facilities to that of the current literature. To achieve this goal, staff members at both MWYF and YMCA were interviewed to obtain the demographics of the students at their facilities and a literature review on the population was conducted to understand the demographics of the students represented in the literature. The 
comparison chart in figure 1 was completed to show the similarities and differences between the two populations. The interviews were successful in determining the demographics that were related to socioeconomic status and home life; however, more complex and sensitive information such as violence, trauma, academic and learning problems, and unstable and disorganized urban neighborhoods was more difficult to obtain. One way to change this barrier in the future would be to get clearance to work closely with and interview the psychologist that works on site.

\section{Figure 1}

\section{Comparing the Demographics of the Students at Two Jacksonville After-care Centers to the}

\section{Current Literature}

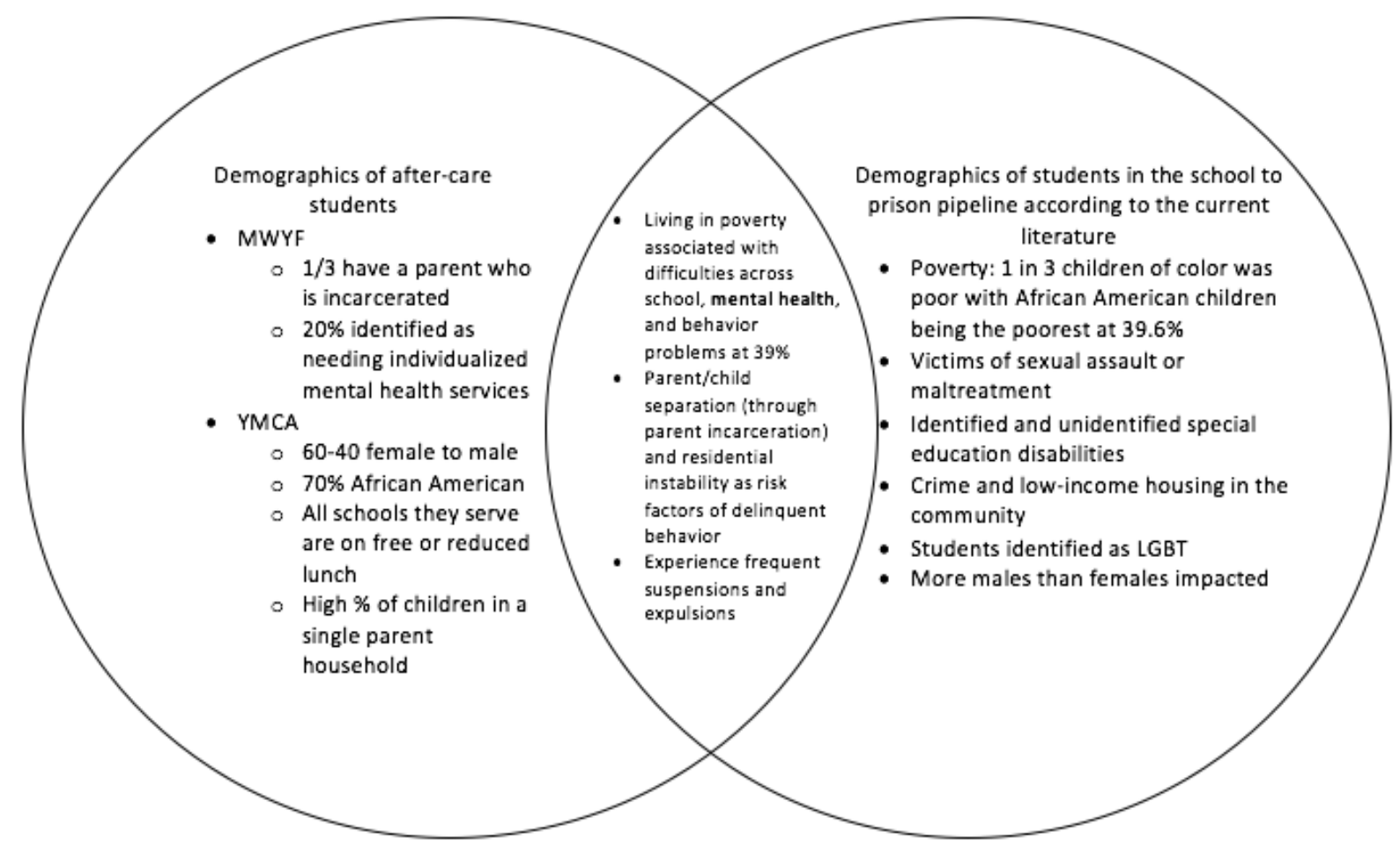

Note. Outer circles show the differences in demographics while the inner circle shows the similarities.

Learning Objective 2 
The second learning objective was to compare the services provided to at-risk youth at two after-care centers. This goal was achieved by observing the classes and activities that took place at MWYF and YMCA outside of the program's 1 hour sessions. Figure 2 depicts the similarities and differences that were noted on site. The process for obtaining information regarding the services provided at both locations went well because it gave the facility an extra staff member to assist in any activities while also allowing the author to develop and establish relationships with the students. One thing that could have been done differently to achieve this goal would be to find time to observe the classes and activities that took place during the program's 1-hour sessions.

Figure 2

Comparing the Services Provided to At-Risk Youth in Two Jacksonville After-Care Centers

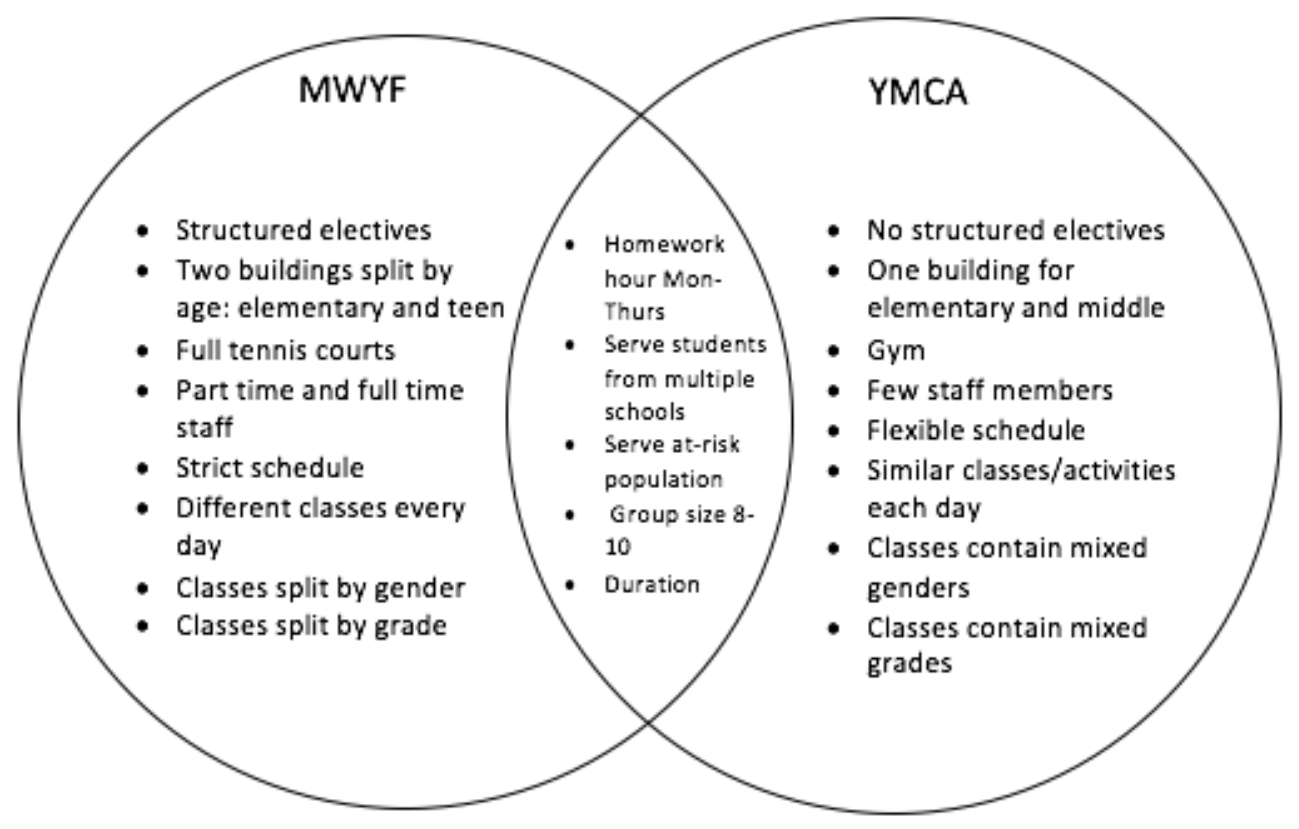

Note. Outer circles show the differences in demographics while the inner circle shows the similarities.

\section{Learning Objective 3}


The third learning objective was to compare and contrast the services provided to at-risk youth in the after-care setting to other settings that serve this population. This goal was achieved by observing virtual meetings with a school counselor at a Jacksonville elementary school.

Figure 3 depicts the similarities and differences that were noted between the 2 settings. The process of completing this learning objective went well by observing the mental health and related services that are provided to the students during the school day, before they get to the after-care settings. One aspect that could have been different for completion of the objective would be to attend the school counselor meetings in person rather than online. In person attendance would have given the author a chance to stay and observe the counselor during times the computer could not be easily transported (i.e. during classroom de-escalation activities); however, the COVID-19 pandemic was one limitation the project faced during development. Figure 3

Comparing the Services Provided to At-Risk Youth in the After-Care Setting to Other Settings

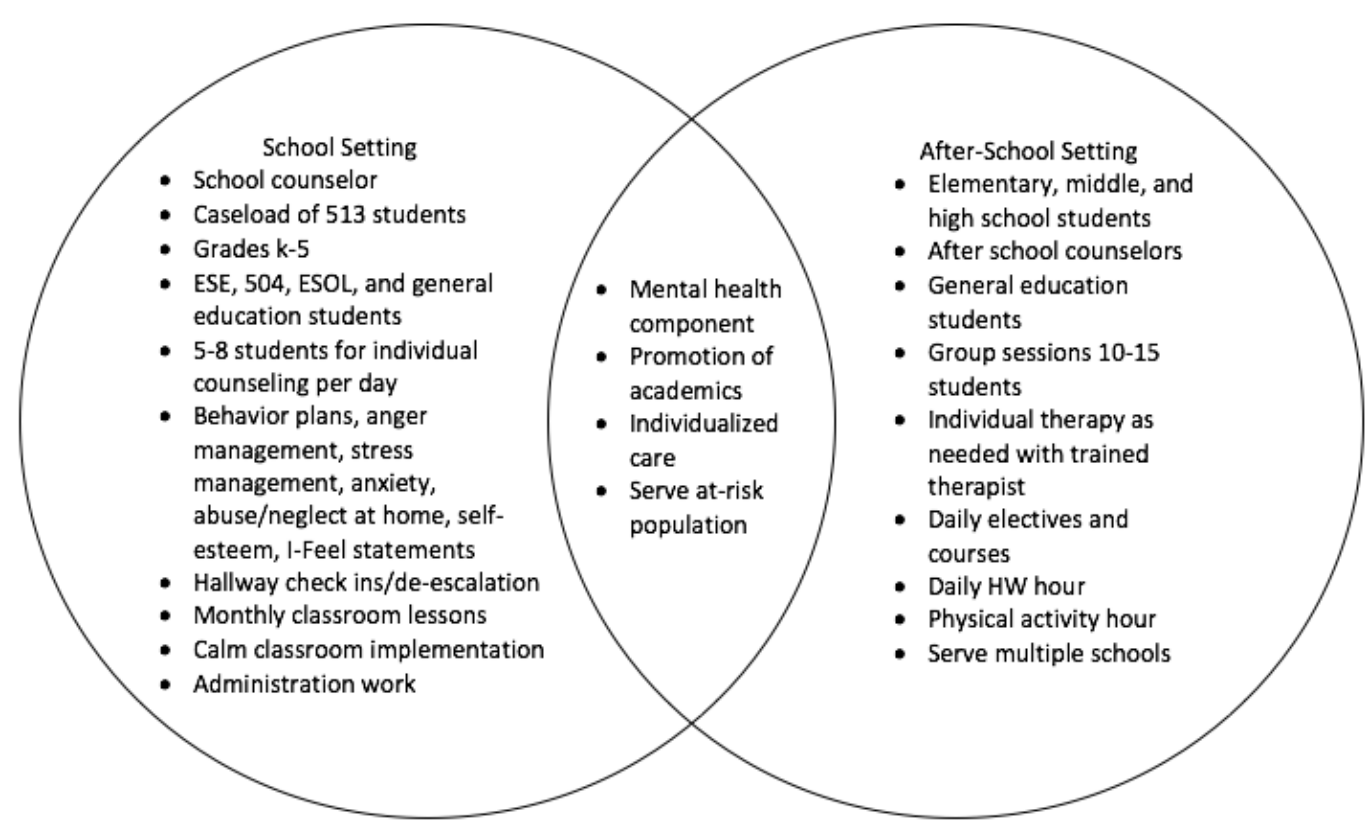


Note. Outer circles show the differences in demographics while the inner circle shows the similarities.

\section{Learning Objective 4}

The fourth learning objective was to assess the relevance of group topics to the students at the host facilities. This goal was achieved by obtaining and reflecting on program session feedback forms that were distributed to all students' post-session each week. One component of the feedback form assessed interest in the session topic and activities, allowing for determination of relevance of each session to the students at both host facilities. Table 2 shows the results on overall interest for each session at both host facilities. According to the data, the most relevant session for the participants was session 6: building confidence through promotion of personal traits while the least relevant was session 2: calming sensory strategies for test taking.

The project was developed under two assumptions that the participations in the group session would be present every day and that they would be honest and accurate in their feedback responses. Both assumptions were inaccurate throughout the progression of the program, which may have impacted the feedback results. Although each group was closed to the same number of students, every session contained a different number of students due to varying reasons students chose not to attend school that day. The varying number of students per session had an impact on the average interest rate per session. Regarding honesty and accuracy with feedback responses, a few sessions contained food rewards which may have impacted their response to the interest scale.

Table 2

Program Feedback on Interest

\begin{tabular}{llllllllll}
\hline Session & 1 & 2 & 3 & 4 & 5 & 6 & 7 & 8 & 9 \\
\hline
\end{tabular}




\begin{tabular}{llllllllll}
\hline MWYF & $8.3 / 10$ & $4.4 / 10$ & N/a & $7.3 / 10$ & $5.8 / 10$ & $7.8 / 10$ & $3.6 / 10$ & $5.8 / 10$ & $5 / 10$
\end{tabular}

Girls

\begin{tabular}{llllllllll}
\hline MWYF & $7 / 10$ & $7.3 / 10$ & $6.5 / 10$ & $7 / 10$ & $10 / 10$ & $10 / 10$ & $9.3 / 10$ & $10 / 10$ & $8.8 / 10$
\end{tabular}

Boys

$\begin{array}{llllllllll}\text { YMCA } & 6.9 / 10 & 5.2 / 10 & 7.1 / 10 & 6.8 / 10 & 8.3 / 10 & 10 / 10 & 7.7 / 10 & 9 / 9 / 10 & 7.5 / 10\end{array}$

G \& B

\section{Learning Objective 5}

The fifth learning objective was to apply an understanding of staff trainings for child abuse and mandated reporting in all sessions. This objective was accomplished by completing all staff trainings online. Refer to appendix $\mathrm{C}$ for the completed certificate for both the child abuse and mandated reporting courses. The objective was met prior to engaging with the students to ensure the author had the appropriate training before beginning the program. The courses took 1 day to complete and all information was appropriate and relevant to working with the population at-risk youth.

\section{Program-Based Objective 1}

The first program-based objective was to implement group sessions targeting mental health to youth at host facilities. To achieve this goal, the author hosted a 1-hour session 1x a week at both MWYF and YMCA. At MWYF, sessions were completed on Wednesday's from 3:30-4:30 pm with the male participants and 4:30-5:30 pm with the female participants. At YMCA, sessions were completed on Thursday's from 4-5 pm with both male and female participants. To provide a visual description and representation of the group sessions that were implemented throughout the program, a program session manual was developed for future use at 
both MWYF and YMCA. Refer to appendix D for the full mental health program session manual.

The program sessions encountered many obstacles along the way; however, were implemented to be best of the author's ability. A few aspects that could have been changed throughout the progression of the program would be education on discipline and education on participant behavior. The first couple sessions were met with the challenge of trying to control a group of students along with building a relationship with them simultaneously. Education on discipline from the staff at the host facilities prior to engagement with the participants would have allowed the author to gain a broader knowledge on the components of discipline. Regarding education on participant behavior, sessions 1 and 2 were not received well by the participants due to the nature of the activity (worksheets) which could have been changed by asking about previous behavior during the needs assessment that was completed prior to engagement.

\section{Program-Based Objective 2}

The second program-based objective was to educate youth on recognizing and coping with positive and negative emotions. This objective was met through the completion of sessions 1: recognizing emotions, 4: recognizing/managing aggression, and 5: conflict resolution. Session effectiveness towards the goal was measured through the use of the program feedback form completed post-session by all participants. Table 3 depicts the results from the effectiveness component of the feedback form. According to the results, session 4 had the highest effectiveness in educating youth on recognizing and coping with positive and negative emotions while session 1 had the lowest effectiveness.

\section{Table 3}

Program Feedback on Effectiveness: Sessions 1, 4, 5 


\begin{tabular}{llcc}
\hline Session & 1 & 4 & 5 \\
\hline MWYF Girls & $7 / 10$ & $8.6 / 10$ & $5.2 / 10$ \\
\hline MWYF Boys & $6.7 / 10$ & $8.8 / 10$ & $8.5 / 10$ \\
\hline YMCA G \& B & $5.9 / 10$ & $4.7 / 10$ & $7.3 / 10$ \\
\hline
\end{tabular}

\section{Program-Based Objective 3}

The third program-based objective was to educate youth on appropriate social and relationship building skills. This objective was met through the completion of sessions 7: identifying positive traits in friendship, 8: promoting positive communication with adults and authority figures, and 9: bullying and cyberbullying prevention. Session effectiveness towards the goal was measured through the use of the program feedback form completed post-session by all participants. Table 4 depicts the results from the effectiveness component of the feedback form. According to the results, session 8 had the highest effectiveness in educating youth on appropriate social and relationship building skills while session 7 had the lowest effectiveness.

\section{Table 4}

Program Feedback on Effectiveness: Sessions 7, 8, 9

\begin{tabular}{llll}
\hline Session & 7 & 8 & 9 \\
\hline MWYF Girls & $3.8 / 10$ & $4 / 10$ & $4.8 / 10$ \\
\hline MWYF Boys & $7.5 / 10$ & $10 / 10$ & $7.4 / 10$ \\
\hline YMCA G \& B & $8.1 / 10$ & $9.3 / 10$ & $7.8 / 10$ \\
\hline
\end{tabular}

\section{Program-Based Objective 4}


The fourth program-based objective was to promote youths' self-confidence and personal strength identification. This objective was met through the completion of session 6: building confidence through the promotion of personal traits. Session effectiveness towards the goal was measured through the use of the program feedback form completed post-session by all participants. Table 5 depicts the results from the effectiveness component of the feedback form. The average effectiveness for promoting youths' self-confidence and personal strength identification was 6.4/10.

Table 5

Program Feedback on Effectiveness: Session 6

\begin{tabular}{ll}
\hline Session & 6 \\
\hline MWYF Girls & $6.2 / 10$ \\
\hline MWYF Boys & $3 / 10$ \\
\hline YMCA G \& B & $10 / 10$ \\
\hline
\end{tabular}

\section{Program-Based Objective 5}

The fifth program-based objective was to promote academic achievement through the development of necessary life skills. The objective was met by completion of sessions 2: calming sensory strategies for test taking and 3: organization and time management. Session effectiveness towards the goal was measured through the use of the program feedback form completed postsession by all participants. Table 6 depicts the results from the effectiveness component of the feedback form. According to the results, session 3 had the highest effectiveness in promoting academic achievement through the development of necessary life skills. Session 2 had the lowest 
effectiveness; however, these results are skewed due to the inability to complete session 3 with the girls at MWYF.

Table 6

Program Feedback on Effectiveness: Sessions 2, 3

\begin{tabular}{lll}
\hline Session & 2 & 3 \\
\hline MWYF Girls & $5.1 / 10$ & N/a \\
\hline MWYF Boys & $6.8 / 10$ & $7 / 10$ \\
\hline YMCA G \& B & $5.7 / 10$ & $4.8 / 10$ \\
\hline
\end{tabular}

\section{Program-Based Objective 6}

The sixth program-based objective was to acquire and review program feedback on group session effectiveness and level of interest from at-risk youth. This objective was completed through the distribution and acquisition of program feedback forms following all sessions. Table 7 depicts all results from the mental health program on effectiveness and interest. Overall, session 6: building confidence through promotion of personal traits had the highest score for interest while session 2: calming sensory strategies for test taking had the lowest score for interest. Regarding effectiveness, session 8: promoting positive communication with adults and authority figures yielded the highest results while sessions 2: calming sensory strategies for test taking and 3: organization and time management yielded the lowest.

\section{Table 7}

Final Program Feedback on Effectiveness and Interest

\begin{tabular}{llllllllll}
\hline Session & 1 & 2 & 3 & 4 & 5 & 6 & 7 & 8 & 9 \\
\hline
\end{tabular}




\begin{tabular}{lllllllllll}
\hline MWYF & I: $8.3 / 10$ & I: $4.4 / 10$ & N/a & I: $7.3 / 10$ & I: $5.8 / 10$ & I: $7.8 / 10$ & I: $3.6 / 10$ & I: $5.8 / 10$ & I:5/10 \\
Girls & E: $7 / 10$ & E:5.1/10 & & E:8.6/10 & E:5.2/10 & E:6.2/10 & E:3.8/10 & E:4/10 & E:4.8/10 \\
\hline MWYF & I: $7 / 10$ & I: $7.3 / 10$ & I: $6.5 / 10$ & I: $7 / 10$ & I: $10 / 10$ & I: $10 / 10$ & I: $9.3 / 10$ & I: $10 / 10$ & I:8.8/10 \\
Boys & E:6.7/10 & E:6.8/10 & E:7/10 & E:8.8/10 & E:8.5/10 & E:3/10 & E:7.5/10 & E: $10 / 10$ & E:7.4/10 \\
\hline YMCA & I: $6.9 / 10$ & I: $5.2 / 10$ & I: $7.1 / 10$ & I: $6.8 / 10$ & I: $8.3 / 10$ & I: $10 / 10$ & I: $7.7 / 10$ & I: $9.9 / 10$ & I:7.5/10 \\
G \& B & E:5.9/10 & E:5.7/10 & E:4.8/10 & E:4.7/10 & E:7.3/10 & E:10/10 & E:8.1/10 & E:9.3/10 & E:7.8/10 \\
\hline Total & I: 7.4 & I: 5.6 & I: 6.8 & I: 7.0 & I: 8.0 & I: 9.2 & I: 6.9 & I: 8.6 & I: 7.1 \\
& E: 6.5 & E: 5.9 & E: 5.9 & E: 7.4 & E: 7 & E: 6.4 & E: 6.5 & E: 7.8 & E: 6.7 \\
\hline
\end{tabular}

\section{Conclusion}

Overall, the learning objectives that guided the project allowed the author to fully explore multiple settings in which at-risk youth are served in the community. Through engagement and observation with this population, mental health prevention and promotion is currently at the forefront of school counseling in Jacksonville, Florida; however, still needs exploration and development at two different after-care centers. The project's purpose of increasing the supportive mental health services provided to at-risk youth in the after-care setting was met by striving to complete all program-based objectives. Program-based objectives were met through the development and implementation of a 9-week program that promoted a variety of mental health concepts and topics tailored to the participations at both locations. The project's purpose directly influenced the overarching problem seen in this population today of the lack of supporting services addressing mental health and occupational performance in after-care settings.

Based on the program results, the participants were the most interested in sessions covering confidence building, conflict resolution, and positive communication with adults. The 
participants also felt that the sessions covering aggression, conflict resolution, and positive communication with adults were the most effective in reaching their targeted goal. In order to continue to combat the problem seen in this population today, steps must be taken in the future to alter the sessions that yielded low interest and low effectiveness in order to create a mental health program that is both engaging and effective to this population in this setting. If these steps are taken to improve the overall results of this mental health program, the population of at-risk youth, the facilities running the program, the profession of OT, and the local community will all greatly benefit by effectively lowering the number of youths entering the school to prison pipeline and remaining on school grounds for the course of their development. 


\section{Chapter V: Discussion and Conclusion}

The program development type project was pursued with the goal of contributing to the lack of supporting services addressing mental health provided to at-risk youth in the after-care setting. The problem of the lack of supporting services was addressed by the project through the development and implementation of a 9-week program addressing multiple mental health topics. The purpose of the project was to increase the supportive mental health services provided to atrisk youth and was carried out at two different Jacksonville after-care settings. In this chapter, the author will interpret the outcomes of the project and discuss the strengths and limitations as well as recommendations for the future.

Based on the program results, the participants were the most interested in sessions covering confidence building, conflict resolution, and positive communication with adults. The participants also felt that the sessions covering aggression, conflict resolution, and positive communication with adults were the most effective in reaching their targeted goal. The author believes that the sessions covering conflict resolution and positive communications with adults

were high in both categories of interest and effectiveness because they had the most participation and had the students up out of their seats more than any other session. The author believes that the session with the lowest scores for interest and effectiveness, session 2: calming sensory strategies for test taking, was due to the involvement of a writing activity rather than a team or game activity. The findings of the project and program can be used to further the research in atrisk youth as well as the profession of occupational therapy (OT).

\section{Interpretation of Findings}

The findings of the program extend the knowledge that currently exists for at-risk youth, after-care settings, and the profession of OT. Regarding the youth, the program gained insight 
into the interest level of many different mental health topics as well as their perception of how effective each session was in meeting goals. This information can be utilized in the future to modify and create an enhanced mental health program that can be used with at-risk youth across the country. The after-care settings gained insight into the type of mental health topics that can and should be discussed with their students along with an introduction to a commonly used OT model that guides the progression of each session. The project also extends the knowledge for the profession of OT by providing evidence on another setting in which services can and should be provided. The findings also show the importance of providing OT services to a new unserved population, at-risk youth.

The current literature on the school to prison pipeline supports the notion that more students today have an increased tendency to become incarcerated and more students today face higher suspension rates than ever before (Schiff, 2018; Mallet, 2016, 2017). Based solely on subjective report from the youth at both facilities, the author believes that the participants in the program faced similar experiences. During sessions 4 and $525 \%$ students reported the frequency at which they themselves or friends of theirs have been suspended in the past week. Suspensions were usually the result of physical and/or verbal altercations with students and/or teachers. While students experienced instances of suspensions and detentions at school, they also showed similar risk factors for the school to prison pipeline discussed in the literature.

According to the current literature on the population of at-risk youth who enter the school to prison pipeline, the risk factors include living in poverty, family dysfunction, violence, trauma, academic and learning problems, mental health difficulties, and unstable and disorganized urban neighborhoods (Mallet, 2017). When comparing these factors to that of the students MWYF 1/3 of the students have a parent who is or was incarcerated, showing the 
representation of students who fall victim to family dysfunction. A good portion, $20 \%$, of the students are also identified as needing individualized mental health services as determined by the psychologist on site, showing the representation of student who show mental health difficulties. At YMCA, a high percentage of children currently live in a single parent household and all of the schools they serve are on free or reduced lunch, showing the representation of students living in poverty. While many students are eligible to receive services within the school system, they are often suspended and/or expelled due to harsh disciplinary actions and therefore no longer receive those services. Even outside of the school system, many after-care programs that assist at-risk youth in academic development do not have effective mental health treatment (Cahill et al., 2020), showing the strong need to increase mental health services provided to youths in this setting.

Current services outside the field of OT addressing the risk factors for involvement in the school to prison pipeline, according to the literature, yielded different results to that the authors program. The different findings come from a focus on differing topics. Whereas many programs in the literature focus mainly on academic improvement and school attendance, the authors program focused more on social/emotional development and mental health promotion. The lack of programs focusing on mental health promotion for this population show that occupational therapists have the opportunity to promote participation in occupations that are crucial for a healthy childhood and set the child up for success throughout their lifetime.

The few studies that focused specifically on OT for the population of at-risk youth showed similar findings to the goals of the authors program. The studies contained topics similar to that of the authors program including self-management and social/communication and strived for the goals of increasing knowledge of coping skills, increasing the youth's sense of self- 
efficacy, and improving the youths' overall mental health. The author believes that current program is supported by the literature of OT services provided to at-risk youth due to the focus on the whole client rather than one aspect of the client. Occupational therapists are educated to apply knowledge of mental and physical health with a focus on participation and the role of occupation to help clients promote health, prevent disability, and overcome or manage health challenges. The profession of OT therefore can view the population of at-risk youth through a new lens with the use of conceptual framework and apply knowledge to expand the knowledge used to serve this population.

The framework that was used to develop the project included the Person-EnvironmentOccupation-Performance (PEOP) and Ecology of Human Performance (EHP) models to focus on each individual client's needs and interests as well as taking a broader perspective to accommodate the needs of the host facilities. The EHP model was used to determine the purpose statement, target setting, and target population through consideration of cultural, physical, temporal, and social environments due to the model's strong focus on context/environment. Two aspects of the EHP model that could have aligned better with the project would be consideration of COVID-19 for the temporal and social aspects. The COVID-19 pandemic affected how many students I was able to work with at once as well as how often the students were allowed to work together. Due to the time restrictions of the project, this aspect was difficult to avoid and required modifications to overcome.

The PEOP model was used to guide and develop interventions at the person and environment level that can shift performance at the occupation level. The project built on the theory by developing all session activities through a top-down perspective to ensure all levels of the client were reached. For example, the activity in session 2 was a zones of regulation 
worksheet that had students consider which emotions fit into which zone and then determine strategies to handle those zones. The strategies discussed were then applied to emotions students may feel before, during, or after taking a test and how they can be handled in the future. The behavior and mental strategies fit under the person factor, the application to the home or school environment fit the environment factor, the test-taking fit under the occupation of education, and the overall performance on a test and feeling when performing on a test can be defined as the intersection between these factors. The model was referenced and utilized through the development of all 9 sessions and allowed the author to ensure the central focus was on how the person-environment-occupation-performance interaction and its related factors contribute to successful occupational performance.

\section{Strengths and Limitations}

The strengths of the project include the use of OT models and mental health topics to shape the content of the program, the use of the program feedback form to determine the perceptions of the participants, and the additional time taken to develop relationships with all participants. The Cole's seven step model was used the guide the progression of each session and included introduction, activity, sharing, processing, generalizing, application, and summary. All 9 sessions utilized this model which allowed the participants to apply the topic used in each session to their lives outside of the session. The feedback form allowed the author to gain insight into the perceptions of the participants by determining the level of interest and effectiveness of each session. The additional time taken to develop relationships with the participants occurred outside the 1-hour session slot in which the author observed and assisting in other classes.

The limitations for the project include the COVID-19 pandemic and the variability in which participants attended the after-care program. The COVID-19 pandemic caused 
participants to not be able to work in groups or teams in which they otherwise would and limited the number of students per session, as a few students got sick during the progression of the project. Another limitation was the variability in which students attend school, and therefore after-care. Many students do not attend school due to sickness, suspension, and/or other personal issues. As a result, each session contained anywhere from 1-8 participants and never contained the full class size. Taking into consideration the strengths and limitations of the project, many recommendations can be made for future projects aiming to achieve similar goals.

\section{Recommendations for the Future}

For future programs aiming to increase the mental health services provided to at-risk youth in the after-care setting, the author recommends utilizing the sessions that yielded the highest results for interest and effectiveness while modifying those with the lowest results for interest and effectiveness. Sessions 4, 5, 6, and 8 showed the highest results while sessions 2, 3, and 7 showed the lowest. Future projects should modify and adapt all activities in session 2, 3 and 7 to increase engagement and interest tailored to their program participants. Another recommendation for the future is the conduct the program at a time in which the COVID pandemic is no longer impacting after-care centers. Implementing the program at a time when social distancing rules do not need to be enforced would allow the students to work together in pairs or teams to increase engagement and allow for more game/team building exercises.

Modifications to the program to improve interest and effectiveness would have the impact of improving overall mental health and occupation performance of at-risk youth in the after-care setting. The participants would be left with strategies to handle negative emotions and difficult situations, promoting recognition of personal traits, and encourage open and honest communication with authority figures. The facilities would also be able to implement these 
sessions into the curriculum in the future with the use of the program portfolio and continue to increase their student's occupational performance. The addition of at-risk youth as an emerging area of practice within OT would provide another setting in which OT practitioners can educate and integrate common practices into the general population.

\section{Conclusion}

A strong occupation-based program designed to promote the mental health of at-risk youth in the after-care setting has the potential to revolutionize the way youths are given and receive preventative treatment. Providing these students with the necessary skills they need to navigate the school and home environment effectively will further lower the instances of students entering the school to prison pipeline. By impacting just one risk factor for involvement in the school to prison pipeline, the program has the ability to transform the lives of young people in the after-care setting. The collaboration of the profession of OT with the staff and students at after-care settings across the country together have the power to also impact local communities by lowering the chances of the students of American entering the juvenile justice system. 


\section{References}

American Occupational Therapy Association. (2016). Occupational therapy's role with mental health in children https://www.aota.org/ /media/Corporate/Files/AboutOT/Professionals/WhatIsOT/MH/Fa cts/MH in Children and Youth fact sheet.pdf

American Occupational Therapy Association. (2015). School Mental Health Toolkit. Retrieved October 31, 2020, from https://www.aota.org/practice/childrenyouth/mental\%20health/school-mental-health.aspx

American Occupational Therapy Association. (2020). The occupational therapy association practice framework: Domain and process, $4^{\text {th }}$ Edition. American Journal of Occupational Therapy, 74(Sup2), 1-87. https://doi.org/10.5014/ajot.2020.74S2001

Baum, C. M., \& Christiansen, C. H. (2005). Person-environment-occupation-performance: An occupation-based framework for practice. In C. H. Christiansen, C. M. Baum, \& J. Basshaugen (Eds.), Occupational therapy: Performance, participation, and well-being $\left(3^{\text {rd }}\right.$ ed.). SLACK Incorporated.

Boyt Schell, B. A., \& Gillen, G. (2019). Willard and Spackman's occupational therapy (13th edition). Wolters Kluwer.

Brown, C., Stoffel, V., \& Muñoz, J. P. (2019). Occupational Therapy in Mental Health: A Vision for Participation: Vol. Second edition. F.A. Davis.

Burke, M. M., \& Dalmage, H. (2016). Special education advocacy in the juvenile justice system: Perspectives from probation officers. Exceptionality, 24(3), 151-164. http://dx.doi.org/10.1080/09362835.2015.1064413 
Burson, K., Fette, C., Orentlicher, M., Precin, P. J., Roush, S. N., \& Kannenberg, K. (2017). Mental health promotion, prevention, and intervention in occupational therapy practice. American Journal of Occupational Therapy, 71, 1-19. https://doi.org/10.5014/ajot.2017.716S03

Cahill, S. M., Egan, B. E., \& Seber, J. (2020). Activity- and occupation-based interventions to support mental health, positive behavior, and social participation for children and youth: A systematic review. American Journal of Occupational Therapy, 74(2), 1-28. https://doi.org/10.5014/ajot.2020.038687

Cahill, S. M., \& Egan, B. E. (2017). Perceptions of occupational therapy involvement in school mental health: A pilot study. Open Journal of Occupational Therapy, 5(1), 1-10. https://doi.org/10.15453/2168-6408.1281

Chi-Kwan Shea, Jackson, N., \& Haworth, C. (2019). Serving high-risk youth in context: Perspectives from Hong Kong. Open Journal of Occupational Therapy (OJOT), 7(3), 116. https://doi.org/10.15453/2168-6408.1566

Cole, M. B., \& Tufano, R. (2008). Applied theories in occupational therapy: A practical approach. SLACK Incorporated.

Cole, M. B. (2018). Group Dynamics in Occupational Therapy: The Theoretical Basis and Practice Application of Group Intervention, Fifth Edition: Vol. Fifth edition. SLACK Incorporated.

Dunn, W., Brown, C., \& McGuigan, A. (1994). The ecology of human performance: A framework for considering the effect of context. American Journal of Occupational Therapy, 48, 595-607. 
Farrington, D. P., Gaffney, H., Lösel, F., \& Ttofi, M. M. (2017). Systematic reviews of the effectiveness of developmental prevention programs in reducing delinquency, aggression, and bullying. Aggression and Violent Behavior, 33, 91-106. https://doi.org/10.1016/j.avb.2016.11.003

Goss v. Lopez [1975] 419 U.S. 565 (Ohio)

Greenberg, M. T., Domitrovich, C. E., Weissberg, R. P., \& Durlak, J. A. (2017). Social and emotional learning as a public health approach to education. Future of Children, 27(1), $13-32$.

Harmon, A. (2020). Individuals with Disabilities Education Act (IDEA). Salem Press Encyclopedia.

Heath, R. A., \& Priest, H. M. (2016). Examining experiences of transition, instability and coping for young offenders in the community: A qualitative analysis. Clinical Child Psychology \& Psychiatry, 21(2), 224-239. http://dx.doi.org/10.1177/1359104515581715

Individuals with Disabilities Education Act, 20 U.S.C. § 1400 (2004)

Jamie R. Yoder, Kelly Whitaker, \& Camille R. Quinn. (2017). Perceptions of recidivism among incarcerated youth: The relationship between exposure to childhood trauma, mental health status, and the protective effect of mental health services in juvenile justice settings. Advances in Social Work, 1, 250. http://doi.org/10.18060/21305

Jenson, J. M., Veeh, C., Anyon, Y., St. Mary, J., Calhoun, M., Tejada, J., \& Lechuga-Peña, S. (2018). Effects of an afterschool program on the academic outcomes of children and youth residing in public housing neighborhoods: A quasi-experimental study. Children and Youth Services Review, 88, 211-217. https://doi.org/10.1016/j.childyouth.2018.03.014 
Khemthong, S. (2017). The effect of occupational therapy on volitional and vocational skills in the Thai juvenile justice system. International Journal of Child Development and Mental Health, 2, 40. https://doaj.org/article/8acbfd7a2b5543b895e112c4a372419f

Kremer, K., Maynard, B., Polanin, J., Vaughn, M., \& Sarteschi, C. (2015). Effects of afterschool programs with at-risk youth on attendance and externalizing behaviors: A systematic review and meta-analysis. Journal of Youth \& Adolescence, 44(3), 616-636. http://doi.org/10.1007/s10964-014-0226-4

Leadley, S., \& Hocking, C. (2017). An occupational perspective of childhood poverty. New Zealand Journal of Occupational Therapy, 64(1), 23-31. https://search.informit.com.au/documentSummary;dn=743435363990857;res=IELNZC

Mahaffey, L. (2016). Occupational therapy's role with mental health in children and youth. https://www.aota.org//media/Corporate/Files/AboutOT/Professionals/WhatIsOT/MH/Facts/MH\%20in\%20Chil dren\%20and\%20Youth\%20fact\%20sheet.pdf

Mallett, C. A. (2017). The school-to-prison pipeline: Disproportionate impact on vulnerable children and adolescents. Education and Urban Society, 49(6), 563-592. http://search.ebscohost.com/login.aspx?direct=true \&db=eric\&AN=EJ1142929\&site=eds$\underline{\text { live }}$

Mallett, C. (2016). The school-to-prison pipeline: A critical review of the punitive paradigm Shift. Child \& Adolescent Social Work Journal, 33(1), 15-24. https://doi.org/10.1007/s10560-015-0397-1 
Merryman, M., Mezei, A., Bush, J., \& Weinstein, M. (2012). The effects of a summer camp experience on factors of resilience in at-risk youth. Open Journal of Occupational Therapy, (1), 3. https://doaj.org/article/98cfd02d43b647e5922aead3fa3fc3eb

Muñoz, J. P., Moreton, E. M., \& Sitterly, A. M. (2016). The scope of practice of occupational therapy in U.S. criminal justice settings. Occupational Therapy International, 23(3), 241-254. http://doi.org/10.1002/oti.1427

National Center for Education Statistics. 2016. Digest of Education Statistics. Washington, DC: U.S. Department of Education. https://nces.ed.gov/programs/digest/2016menu tables.asp

National Council on Disability. (2015). Breaking the school-to-prison pipeline for students with disabilities. National Council on Disability. https://eric.ed.gov/contentdelivery/servlet/ERICServlet?accno=ED571874

Newman, B. J., \& Hartman, T. K. (2019). Mass shootings and public support for gun control. British Journal of Political Science, 49(4), 1527-1553. https://doi.org/10.1017/S0007123417000333

Payne, S. (2008). Applying the person-environment-occupation model to a DCD population. http://www.ergoterapilforbarn.no/pdf/Sally PEO.pdf

Ryan, S. (2019). "You gotta do It right the first time": OT's role in middle school to college transitions for youth in an underserved community. AJOT: American Journal of Occupational Therapy, (S1). https://doi.org/10.5014/ajot.2019.73S1-PO4055

Schiff, M. (2018). Can restorative justice disrupt the 'school-to-prison pipeline?' Contemporary Justice Review, 21(2), 121-139. https://doi.org/10.1080/10282580.2018.1455509 
Shea, C.-K., Jackson, N., \& Haworth, C. (2019). Serving high-risk youth in context: Perspectives from Hong Kong. Open Journal of Occupational Therapy (OJOT), 7(3), 1-16. https://doi.org/10.15453/2168-6408.1566

Shea, C.-K., \& Jackson, N. (2015). Client perception of a client-centered and occupation-based intervention for at-risk youth. Scandinavian Journal of Occupational Therapy, 22(3), 173-180. http://doi.org/10.3109/11038128.2014.958873

Shea, C.-K., \& Siu, A. M. H. (2016). Engagement in play activities as a means for youth in detention to acquire life skills. Occupational Therapy International, 23(3), 276-286. https://doi.org/10.1002/oti.1432

Strong, S., Rigby, P., Stewart, D., Law, M., Letts, L., \& Cooper, B. (1999). Application of the person-environment-occupation model: A practical tool. Canadian Journal of Occupational Therapy, 66(3), 122-133. https://doi.org/10.1177/000841749906600304

Taylor, R. D., Oberle, E., Durlak, J. A., \& Weissberg, R. P. (2017). Promoting positive youth development through school-based social and emotional learning interventions: A metaanalysis of follow-up effects. Child Development, 88(4), 1156-1171. http://dx.doi.org/10.1111/cdev.12864

Tokolahi, E., Hocking, C., \& Kersten, P. (2016). Development and content of a school-based occupational therapy intervention for promoting emotional well-being in children. Occupational Therapy in Mental Health, 32(3), 245-258. https://doi.org/10.1080/0164212X.2015.1129522

U.S. Department of Education. (2016, July 18). School climate and discipline: Know the data. https://www2.ed.gov/policy/gen/guid/school-discipline/data.html 
Weissberg, R. P. (2019). Promoting the social and emotional learning of millions of school children. Perspectives on Psychological Science, 14(1), 65-69. https://doi.org/10.1177/1745691618817756

Wiley, K. E., Anyon, Y., Yang, J. L., Pauline, M. E., Rosch, A., Valladares, G., Downing, B. J., \& Pisciotta, L. (2018). Looking back, moving forward: Technical, normative, and political dimensions of school discipline. Educational Administration Quarterly, 54(2), 275-302. http://dx.doi.org/10.1177/0013161X17751179

World Health Organization. (2013). Mental health action plan 2013-2020. Geneva: Author.

Wylie, L. E., \& Rufino, K. A. (2018). The impact of victimization and mental health symptoms on recidivism for early system-involved juvenile offenders. Law \& Human Behavior (American Psychological Association), 42(6), 558-569. http://doi.org/10.1037/lhb0000311

Yoder, J. R., Whitaker, K., Quinn, C. R. (2017). Perceptions of recidivism among incarcerated youth: The relationship between exposure to childhood trauma, mental health status, and the protective effect of mental health services in juvenile justice settings. Advances in Social Work, 1, 250. https://doi.org/10.18060/21305

Zajac, K., Sheidow, A. J., \& Davis, M. (2015). Juvenile justice, mental health, and the transition to adulthood: A review of service system involvement and unmet needs in the U.S. Children and Youth Services Review, 56, 139-148. http://doi.org/10.1016/j.childyouth.2015.07.014 


\section{Appendix}

\section{Appendix A}

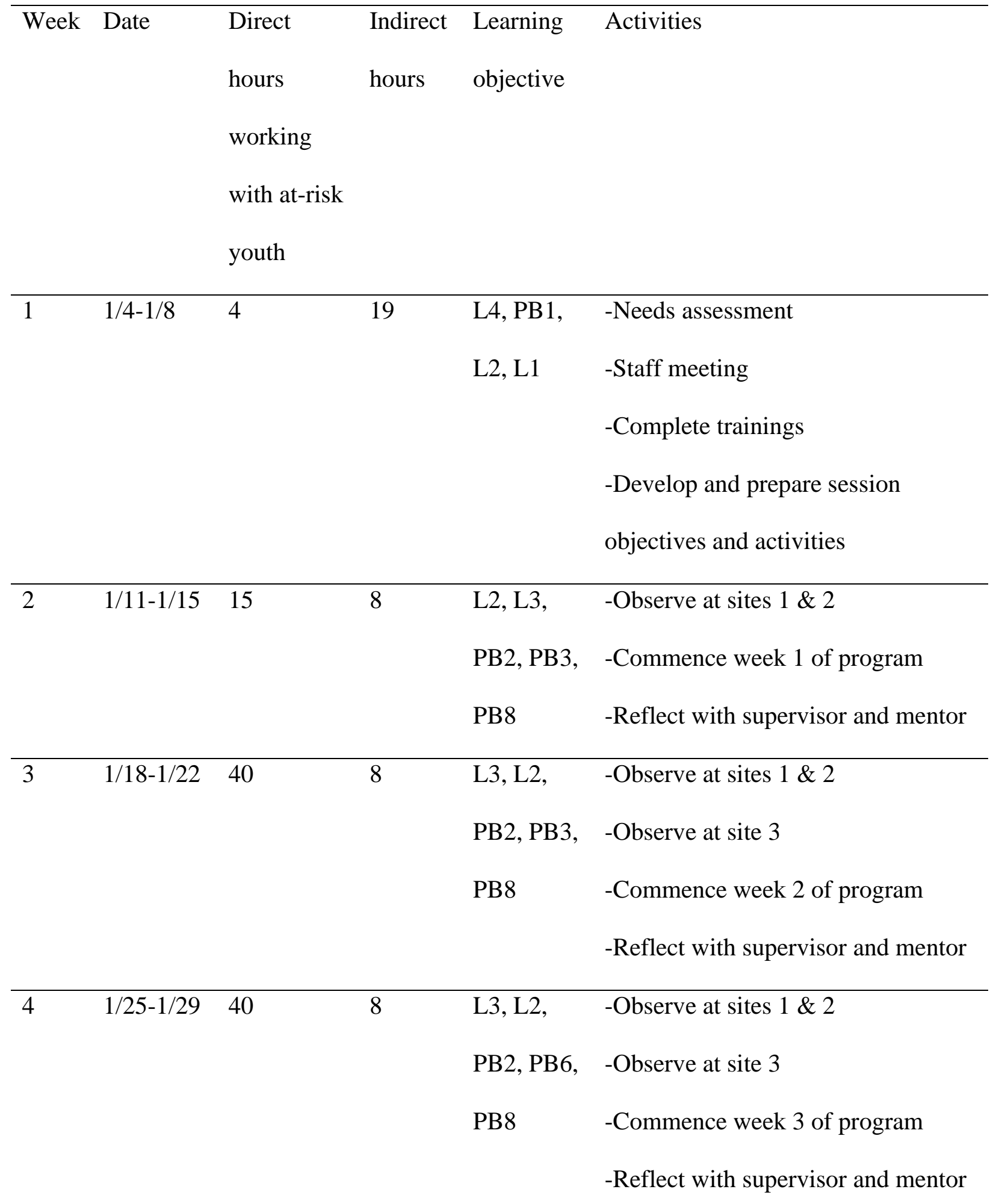




\begin{tabular}{|c|c|c|c|c|c|}
\hline \multirow[t]{4}{*}{5} & $2 / 1-2 / 5$ & 40 & 6 & L3, L2, & -Observe at sites $1 \& 2$ \\
\hline & & & & PB2, PB3, & -Observe at site 3 \\
\hline & & & & PB8 & -Commence week 4 of program \\
\hline & & & & & -Reflect with supervisor and mentor \\
\hline \multirow[t]{4}{*}{6} & $2 / 8-2 / 12$ & 41 & 6 & L3, L2, & -Observe at sites $1 \& 2$ \\
\hline & & & & PB2, PB3, & -Observe at site 3 \\
\hline & & & & PB8 & -Commence week 5 of program \\
\hline & & & & & -Reflect with supervisor and mentor \\
\hline \multirow[t]{4}{*}{7} & $2 / 15-2 / 19$ & 41 & 6 & PB2, PB5, & -Observe at sites $1 \& 2$ \\
\hline & & & & PB7, PB8 & -Observe at site 3 \\
\hline & & & & & -Commence week 6 of program \\
\hline & & & & & -Reflect with supervisor and mentor \\
\hline \multirow[t]{4}{*}{8} & $2 / 22-2 / 27$ & 41 & 6 & PB2, PB4, & -Observe at sites $1 \& 2$ \\
\hline & & & & PB7, PB8 & -Observe at site 3 \\
\hline & & & & & -Commence week 7 of program \\
\hline & & & & & -Reflect with supervisor and mentor \\
\hline \multirow[t]{5}{*}{9} & $3 / 1-3 / 5$ & 41 & 8 & PB2, PB4, & -Observe at sites $1 \& 2$ \\
\hline & & & & PB7, PB8 & -Observe at site 3 \\
\hline & & & & & -Commence week 8 of program \\
\hline & & & & & -Reflect with supervisor and mentor \\
\hline & & & & & -Write chapters $4 \& 5$ \\
\hline \multirow[t]{2}{*}{10} & $3 / 8-3 / 12$ & 0 & 7 & PB8 & No school / after-care \\
\hline & & & & & Spring break \\
\hline
\end{tabular}




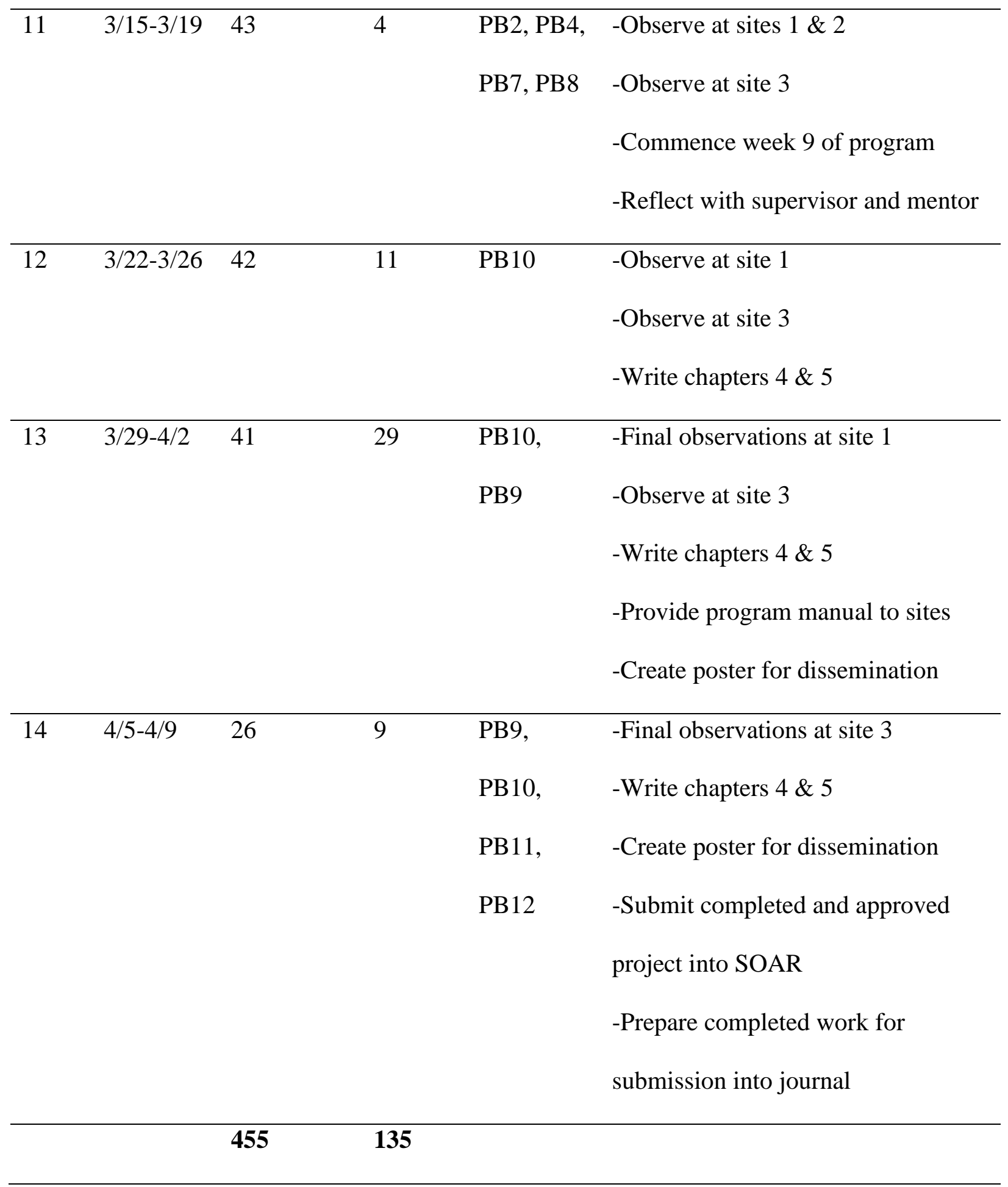




\section{Appendix B}

\section{Week One Reflection}

Group activity:

1. What would you rate your level of interest in this activity?

$\begin{array}{lllllllllll}0 & 1 & 2 & 3 & 4 & 5 & 6 & 7 & 8 & 9 & 10\end{array}$

2. What would you rate the effectiveness of this activity in reaching the objective?

$\begin{array}{lllllllllll}0 & 1 & 2 & 3 & 4 & 5 & 6 & 7 & 8 & 9 & 10\end{array}$

3. What would you change about this activity to make it better? 


\section{Appendix C}

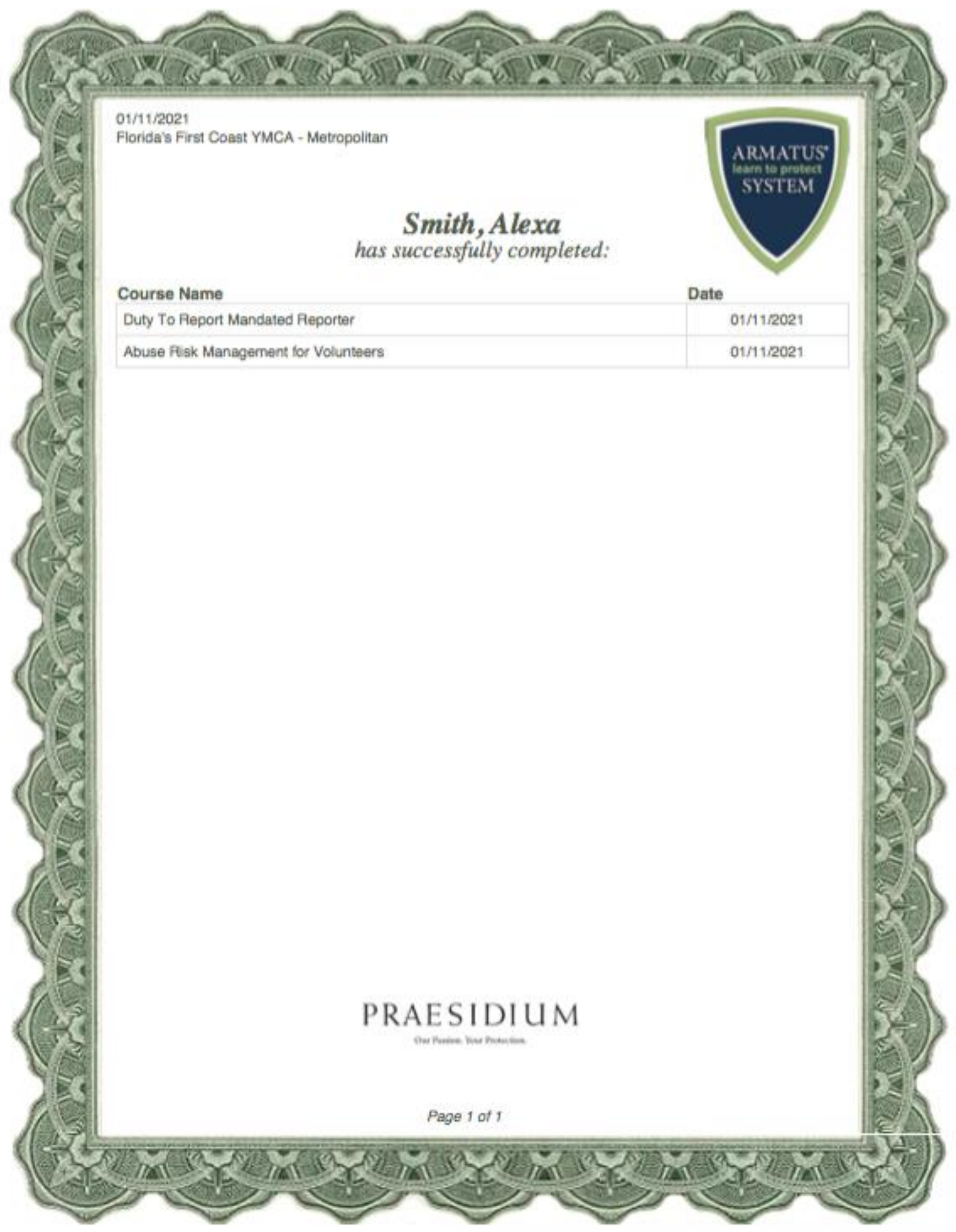


Appendix D

AN OCCUPATION-BASED PROGRAM

to PROMOte MENTAL HEALTH OF

AT-RISK YOUTH IN AN AFTER-CARE

\section{DEVELOPED BY: \\ ALEXA SMITH, OTDS}




\section{Program Sessions}

Cole's Seven Step Model....................................................................

Session 1: Recognizing Emotions.........................................................4

Session 2: Calming Sensory Strategies for Test Taking................................

Session 3: Organization \& Time Management............................................9

Session 4: Recognizing \& Managing Aggression.......................................10

Session 5: Conflict Resolution..................................................................12

Session 6: Building Confidence Through Promotion of Personal Traits.............13

Session 7: Identifying Positive Traits in Friendship....................................15

Session 8: Promoting Positive Communication with Adults \& Authority Figures... 18

Session 9: Bullying \& Cyberbullying Prevention............................................. 19 


\section{Cole's Seven Step Model}

Step 1: Introduction

- Leader introduces themselves and the session to the group

- Warm up: exercise that captures the group's attention and prepares them for the activities to follow

- Leader clearly explains the purpose of the group with a brief outline of the session

Step 2: Activity

- Group activity that will be focused on the session topic and include all members

- Leader must consider timing, goals, physical/mental capacities of members, and adaptation of an activity

Step 3: Sharing

- Each member is invited to share his/her work or experience with the group

Step 4: Processing

- Involves members expressing how they feel about the experience, the leader, alid each other

Step 5: Generalizing

- Leader mentally reviews the group's responses to the activity and tries to sum them up with a few general principles

Step 6: Application

- Leader helps the group understand how principles learning during the session can be applied to everyday life

Step 7: Summary

- Verbally emphasize most important aspects of the group 


\section{Session 1: Recognizing Emotions}

Introduction:

- Introduce yourself and purpose of the session- educating youth on recognizing positive and negative emotions

- Warm up: Deserted island memory game

- Prompt students with the question: If you were going to a deserted island, what is one item you would bring?

- Each student must say every answer that came before them before saying their answer

Activity:

- Emotional acting

- Leader will have 10-15 index cards with a different emotion on each card

- Students will be prompted to take a card one at a time and act out the emotion they picked

- One student in the group must correctly guess which emotion is being acted out Sharing:

- The student who correctly guesses the emotion will then share what makes them feel that way or a story of a recent time they felt that way

Processing:

- Students will be prompted to share their feelings with the following questions: how did you like that activity? Do you feel you could easily recognize all emotions? Which ones were easy/difficult? Any overlapping emotions? Positive vs. negative?

Generalizing:

- Leader will discuss general principles from students' responses

Application:

- Students will be prompted to apply principles discussed to the school environment with the following questions: Which emotions do you notice at school? Can you think of a time where a negative emotion led to a negative outcome? What positive emotion could have been used to change the outcome?

Summary 


\section{Session 2: Calming Sensory Strategies for Test Taking}

Introduction:

- Introduce yourself and purpose of the session- educating youth on recognizing positive and negative emotions

- Warm up: paper airplane send-off

- Prompt students to write down a worry they have about taking a test

- Demonstrate constructing a paper airplane and see who can send their worry off the farthest

Activity:

- Zone of regulation worksheet

- Prompt students to split up into groups of 2 and provide students with activity worksheet (reference on page 6)

- Prompt students to match the emotion to the correct zone it belongs in

- Blue = low arousal, need to recharge

- Green = good state, should proceed again

- Yellow = individual should pause and assess the situation

- Red = individual needs to take a break and use a different strategy

Sharing:

- All students are prompted to share where they placed each emotion

- All students are then prompted to share strategies they can use the manage the emotions in each zone

Processing:

- Students will be prompted to answer the following questions: What did you guys think about that activity? Did anyone learn any new strategies?

Generalizing:

- Review strategies and when you can use each

Application:

- Which strategies discussed or new strategies can be used to prepare for a test? Can any be used for multiple zones? What strategies are used during a test? Summary: 


\section{ZONES OF REG LATION \\ Match the emotion to the zone you think it belongs in}

\section{BLUE}

GREEN
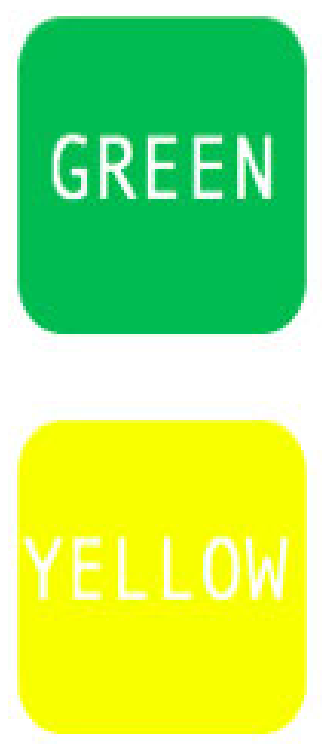

\section{RED}

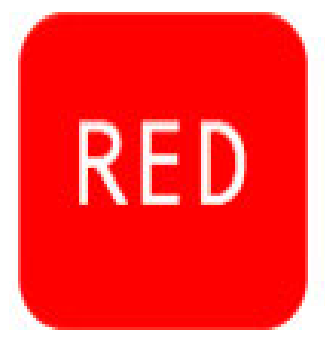

\begin{abstract}
Angry
Hyper

Bored

Focused

Lonely

Excited

Out of

control
\end{abstract}

Happy

Frustrated

Sad

Elated

Calm

Terrified

Nervous 


\section{ZONES OF REGULATION}

Match the emotion to the zone you think it belongs in

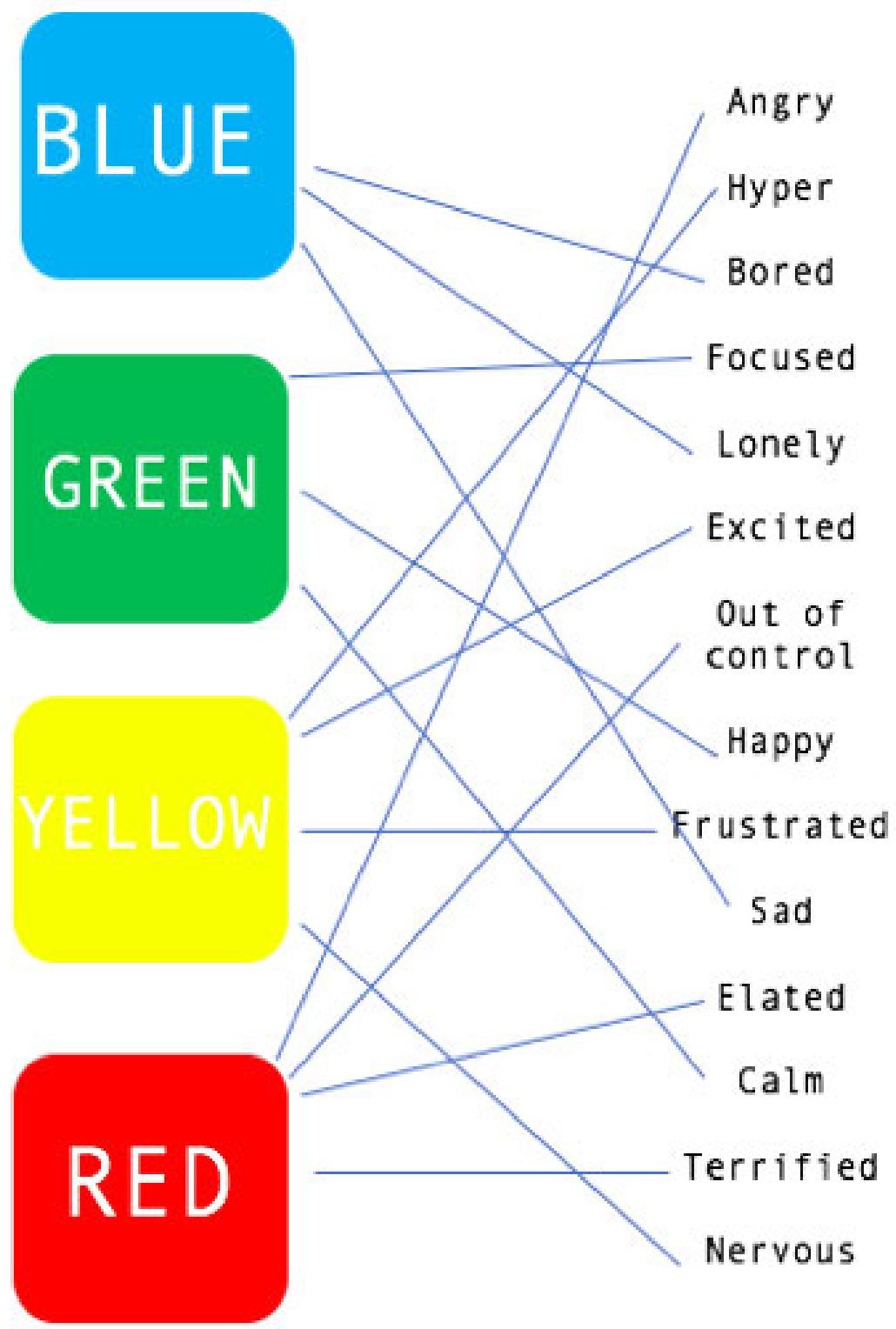




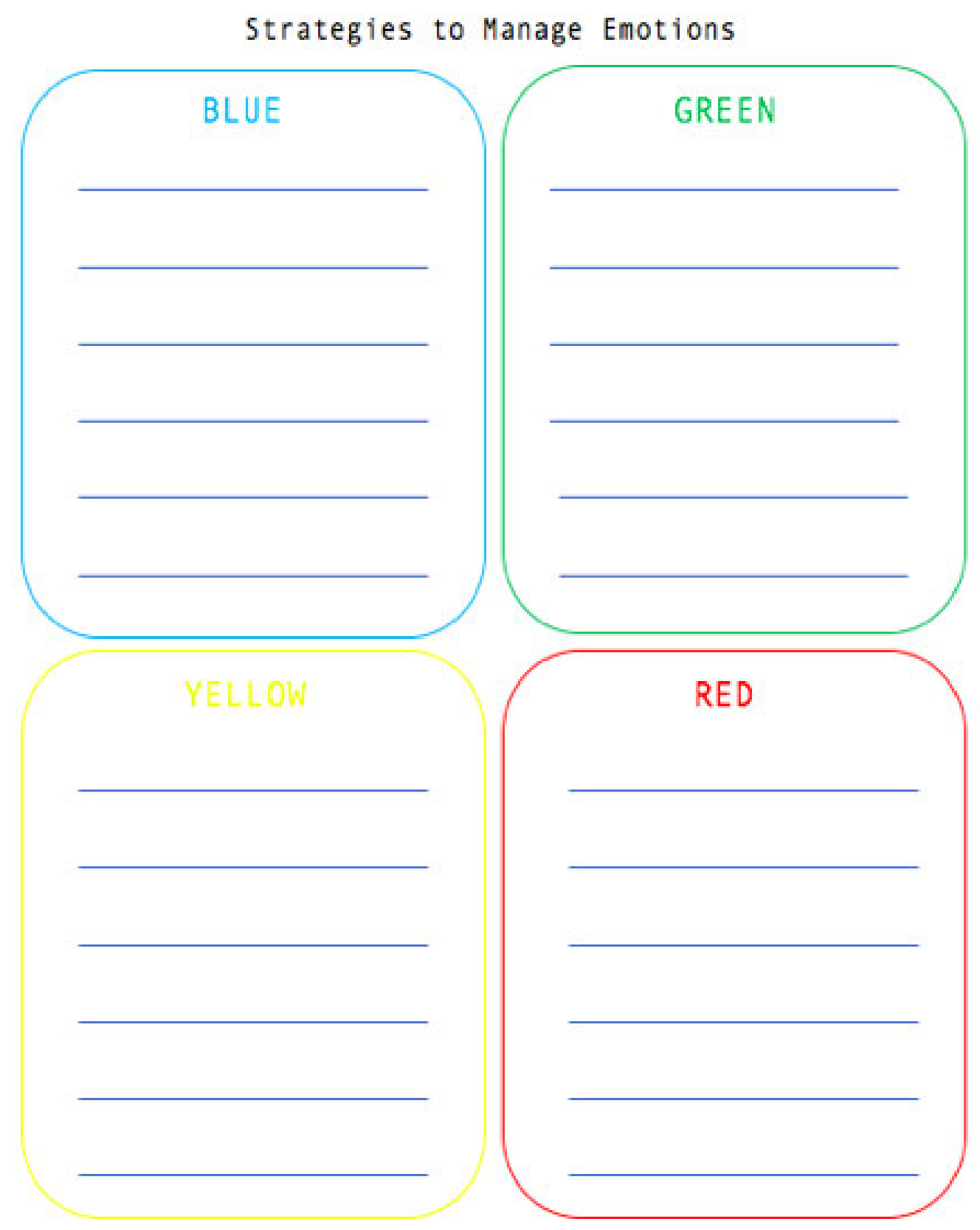




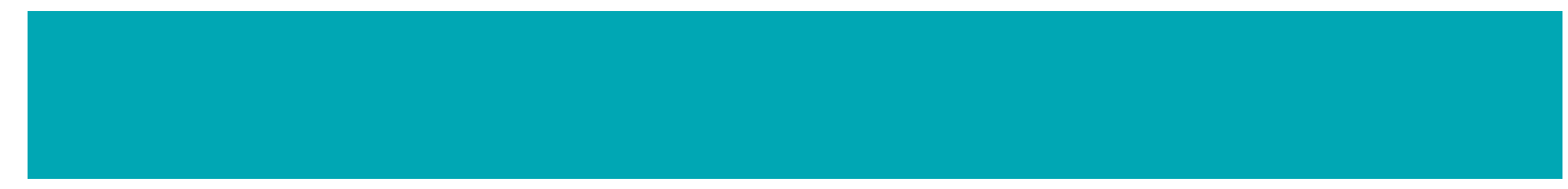

\section{Session 3: Organization and Time Management} Introduction:

- Introduce yourself and purpose of the session-promote academic achievement through the development of necessary life skills

- Warm up: Students will each be given an index card and are encouraged to write down 5 productive tasks they did yesterday

- Students are then encouraged to write down 1 unproductive task they did yesterday

- Explain that this is the ratio we typically want in a day: 5 productive tasks for every 1 unproductive task

Activity:

- Organization game: Students will be split into two groups and will each be given 5 card categories and 50 cards to categorize into each category (10 cards per category)

- Encourage students to work together and develop a system for organization during the game

- The first team to categorize all cards correctly the fastest wins

- Ex. categories: rappers, Florida cities, video games, Tik Tok, and professional teams

Sharing:

- What was your team's strategy for organizing the cards? What do you think worked well and what do you think could have gone better?

Processing:

- Was this task easy/hard? Which categories were the hardest to figure out? What aspects of the tasks did you need to consider?

Generalizing:

- Review strategies for organization and time management Application:

- What strategies discussed can be utilized at school? What supplies do you use to stay organized and manage your time? How do you think this will change as you continue to move up in grade school?

Summary: 


\section{Session 4: Recognizing and Managing Aggression}

Introduction:

- Introduce yourself and purpose of the session- educating youth on recognizing positive and negative emotions

- Warm up: making choices game

- Split the room into side $A$ and $B$ and encourage students to pick a side of the room to run to after hearing different statements about managing aggression

- Use the following statements for game:

- When I am angry, I am more likely to

- A) express my feelings

B) keep it all inside

- A) hit something

B) run away

- A) yell

- A) react quickly

B) cry

- A) feel hot/turn red

B) think about my next actions

B) clench my fists

- When I am trying to calm down, I am more likely to:

$\begin{array}{ll}\text { - A) take deep breaths } & \text { B) listen to music }\end{array}$

$\begin{array}{ll}\text { - A) go for a walk } & \text { B) talk about my feelings }\end{array}$

$\begin{array}{lll}\text { - A) call a friend } & \text { B) call my mom or dad }\end{array}$

- When I think about being angry in the future, I want to:

$\begin{array}{lll}\text { - A) lash out } & \text { B) work on controlling my anger }\end{array}$

$\begin{array}{ll}\text { - A) learn how to cope } & \text { B) stay the wayl am }\end{array}$

Activity:

- Have students split into 3 groups and discuss healthy vs. unhealthy coping strategies to then share with the class

- Provide each group a scenario card that they must use to determine what coping strategy was used and replace any negative coping strategy with a positive one

Sharing:

- Based on their scenario, groups must answer the following questions: what consequences might result from this individual's unhealthy coping strategy? What healthy coping strategies could be helping for this individual? What barriers might be preventing the individual from using healthy coping strategies? 


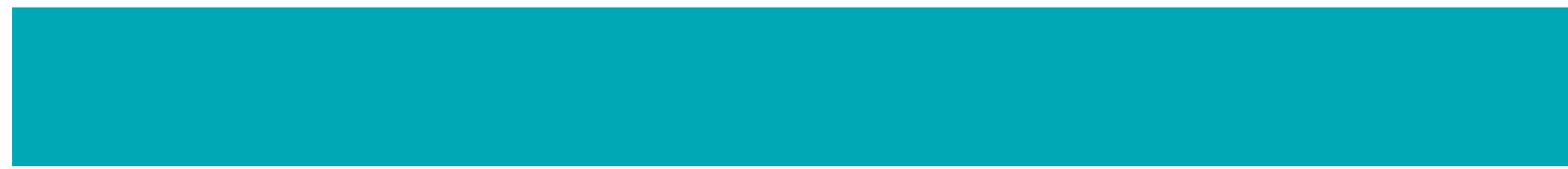

\section{Session 4: Recognizing and Managing Aggression cont. Processing:}

- Prompt the students to process the information discussed with the following questions: is it difficult to actually think about the ways you react in certain situations? Do you feel as though there are many healthy alternatives to the unhealthy strategies? Consider which healthy and unhealthy strategies you use the most.

\section{Generalizing:}

- Review all healthy vs. unhealthy coping strategies discussed and ways to replace unhealthy strategies with healthy ones

Application:

- Turn to discussion to specific scenarios that the students face

- In what ways does aggression show which at school? In what ways do you deal with aggression negatively at school? Positively?

- Think about a time where you could have used a positive strategy rather than a negative one to change the outcome of a conflict or situation

Summary:

\section{Scenarios used for activity:}

\section{Example Scenarios}

Noelle has a research paper due in one of her classes. Because the paper will require so much work, Noelle feels anxious every time she thinks about it. When Noelle distracts herself with other activities, she feels better. Noelle uses the coping strategy of procrastination to avoid her feelings of anxiety. This helps her feel better now, but will cause problems in the long run.

Juan feels jealous whenever his wife spends time with her friends. To control the situation, Juan uses insults to put down his wife's friends, and he demands that his wife stay home. When Juar's wife caves to his demands, he feels a sense of relief. Juan uses the coping strategy of aggression to avoid the discomfort of jealousy.

Rebecca is angry about being passed over for a promotion at work. Rather than discussing the situation with her boss and trying to improve her work performance, she holds onto her anger. Rebecca has learned to manage her anger by drinking alcohol. Drinking numbs Rebecca's anger temporarily, but the problems at work remain unresolved. 


\section{Session 5: Conflict Resolution}

Introduction:

- Introduce yourself and purpose of the session- educating youth on recognizing positive and negative emotions

- Warm up: 4 words activity

- Each student will be given a small piece of paper and a pencil

- Students will be instructed to write down 4 words that come to mind when they hear the word 'conflict'

- Students will then pair up with another student and together they must agree on the best 4 words out of their 8

- Students will continue to pair up until the whole class is working together to determine the final 4 words

Activity:

- Students will group up into pairs and each pair will be given 2 conflict cards with varying scenarios

- Students will then act out the scenarios: first with a negative result and second with a positive result

Sharing:

- Students who are not acting at the time are prompted to answer the following questions: what went wrong? What went right? What could have gone better?

Processing:

- Prompt a discussion with the following questions: are you rethinking any decision you've made in the past? Has anyone had these conflicts happen to them? How did you handle it?

Generalizing:

- Review discussed conflict starters and stoppers

Application:

- Prompt students to think about how being aware of conflict starters and stoppers can help them academically

Summary: 


\section{Session 6: Building Confidence Through Promotion of Personal Traits} Introduction:

- Introduce yourself and purpose of the session- educating youth on recognizing positive and negative emotions

- Warm up: Two truths and a lie

- Students will be prompted to think about two truths and one lie about themselves that they will share with the class

- The class must then guess which statement about the student is a lie Activity:

- Students will pair up and each pair will be given a personality tic tac toe game sheet (see next page)

- Students will use M\&M's as game pieces and answer the question in the box that corresponds to each move

- Optional

- Students may also take a quick personality test if desired

- https://my-personality-test.com/true-colours

Sharing:

- Students will be prompted to share some of the answers they discussed during the game

- Did anyone have anything in common? Any differences?

Processing:

- Students will be prompted with the following questions: Did you learn anything new about yourself? Did you learn anything new about any of your classmates?

Generalizing:

- Discuss which interested and personality traits were discussed

Application:

- Students will be prompted with the following question: How can you apply these traits and interests to help you determine your future career?

Summary: 


\begin{tabular}{l|l|l}
$\begin{array}{l}\text { What is your best personality } \\
\text { trait? }\end{array}$ & $\begin{array}{l}\text { What are some } \\
\text { characteristics of your } \\
\text { personality? }\end{array}$ & $\begin{array}{l}\text { What is your best personality } \\
\text { trait? }\end{array}$ \\
\hline $\begin{array}{l}\text { If you could change any } \\
\text { aspect of your personality, } \\
\text { what would it be? }\end{array}$ & $\begin{array}{l}\text { In what way has your } \\
\text { personality changed? Why } \\
\text { has it changed? }\end{array}$ & $\begin{array}{l}\text { Are male and female } \\
\text { personalities different? }\end{array}$ \\
\hline $\begin{array}{l}\text { What kind of people do you } \\
\text { get along well with? }\end{array}$ & $\begin{array}{l}\text { What personality types are } \\
\text { you attracted to? }\end{array}$ & $\begin{array}{l}\text { Is your personalitymore } \\
\text { similarto your mother's or } \\
\text { father's? }\end{array}$ \\
\hline $\begin{array}{l}\text { Doyou think birth order } \\
\text { makes a difference in your } \\
\text { personality? }\end{array}$ & $\begin{array}{l}\text { Doyou think we are born } \\
\text { with our personalities, ordo } \\
\text { we develop them because of } \\
\text { what happens to us? }\end{array}$ & $\begin{array}{l}\text { Whatpersonalitytraits do } \\
\text { you consider important in a } \\
\text { good friend/a boss/a } \\
\text { partner? }\end{array}$ \\
& &
\end{tabular}




\section{Session 7: Identifying Positive Traits in Friendship}

Introduction:

- Introduce yourself and purpose of the session- educating youth on appropriate social and relationship building skills

- Warm up: Who do you admire?

- Students are instructed to think about 3 people they admire or look up to and why

- Conduct short discussion with the class

Activity:

- Friendship stoplight game: students will be given 15 scenario cards and as a class they must decide together whether the scenario fits into one of three categories:

healthy/good signs in a friendship, warning signs in a friendship, or unhealthy/bad signs in a friendship

- Refer to the following pages for the scenario cards and answers

Sharing:

- Students must explain their rationalization for each scenario card categorization

- Students are then prompted to think about and share personal experiences for each scenario card

Processing:

- Students will be prompted with the following questions: were these scenarios easy to categorize? Are they easy to identify and categorize in real life? Why or why not?

Generalizing:

- Summarize key points regarding identification of positive traits in friendships Application:

- Students will be prompted with the following questions: How do you think some of the more negative traits (yellow/red) may affect someone academically? Positive or negative consequences?

Summary: 


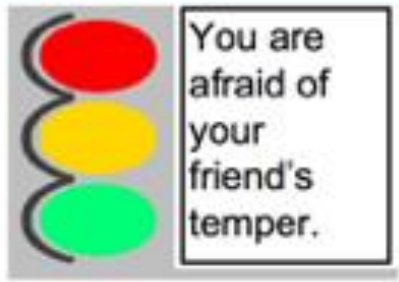

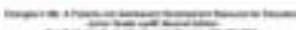

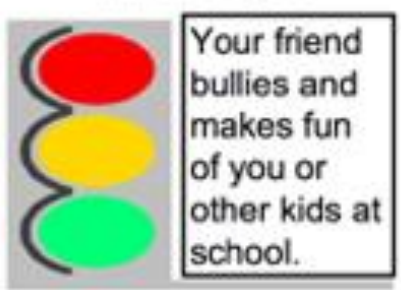

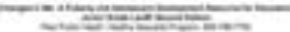

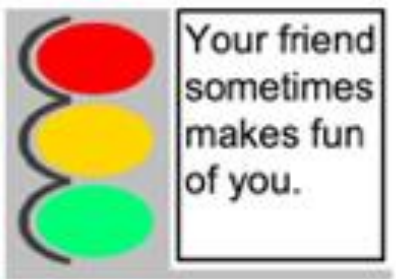

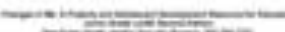

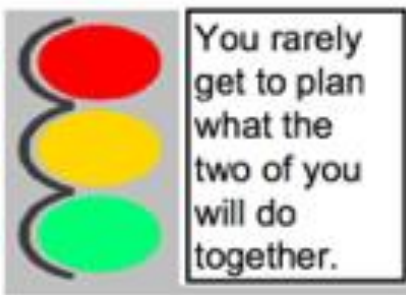

mon-mon

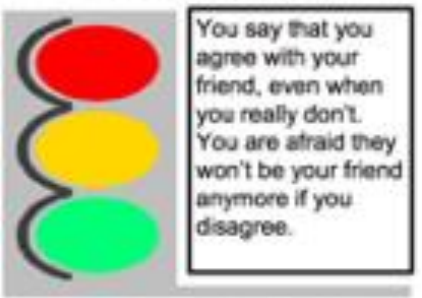

mom
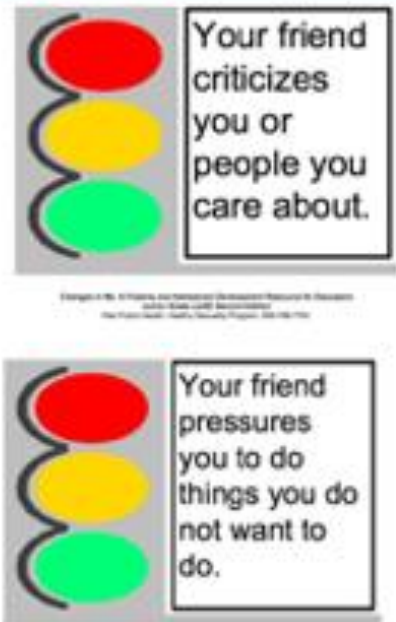

-

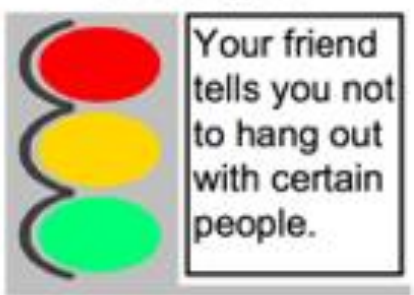

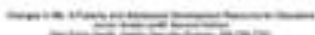

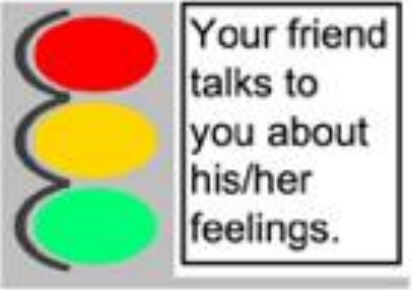

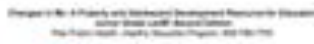

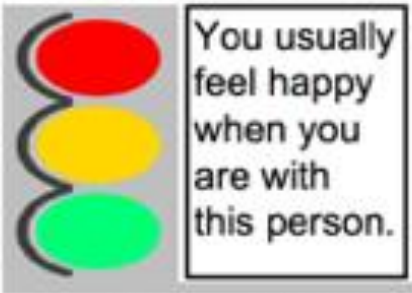

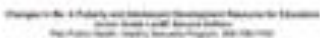

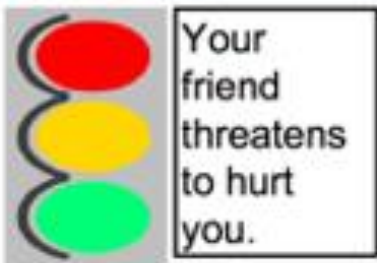

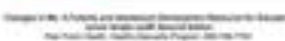

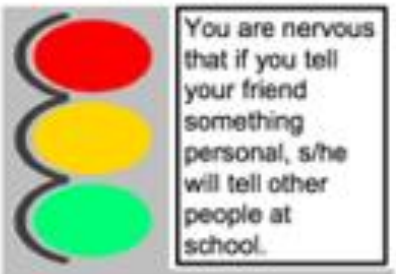

-

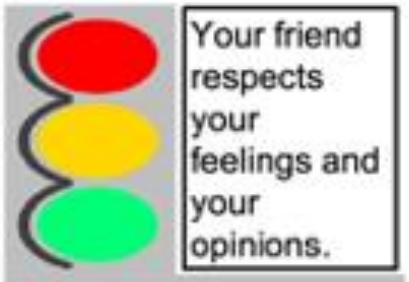

-

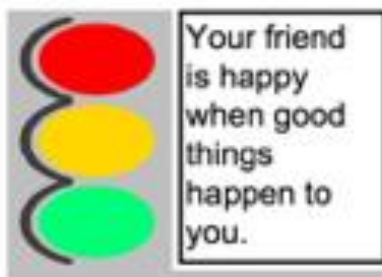

-

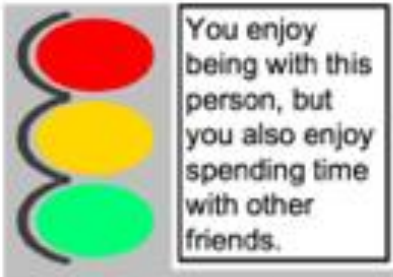

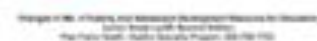


RED LIGHT: These are unhealthy/bad signs in a friendship.

1. You are afraid of your friend's temper.

2. Your friend criticizes you or people you care about.

3. Your friend threatens to hurt you.

4. Your friend bullies and makes fun of you or other kids at school.

5. Your friend pressures you to do things you do not want to do.

YELLOW LIGHT: These are warning signs in a friendship.

6. You are nervous that if you tell your friend something personal, s/he will tell other people at school.

7. Your friend sometimes makes fun of you.

8. You rarely get to plan what the two of you will do together.

9. Your friend tells you not to hang out with certain people.

10. You say that you agree with your friend, even when you really don't. You are afraid they won't be your friend anymore if you disagree.

GREEN LIGHT: These are healthy/good signs in a friendship.

11. You usually feel happy when you are with this person.

12. Your friend respects your feelings and your opinions.

13. Your friend talks to you about his/her feelings.

14. Your friend is happy when good things happen to you.

15. You enjoy being with this person, but you also enjoy spending time with other friends. 
Session 8: Promoting Positive Communication with Adults and Authority Figures

Introduction:

- Introduce yourself and purpose of the session- educating youth on appropriate social and relationship building skills

- Warm up: Who is the oldest?

- Students are instructed to line up in order of the earlier birthday to the latest without talking

- Quick discussion regarding the strategies used to determine birth order

Activity:

- Divide the class into 2 groups

- The groups must decide on 1 member of the team to leave the classroom and decide on a specific object

- Teams must then determine the chosen object by asking yes or no questions only

- The first team to correctly identify the object is the winner

Sharing:

- Discuss the strategies each student or team used to narrow down the object in question

Processing:

- Prompt the students to share how open ended questions differ from that of closed ended questions and in which situations each is appropriate

Generalizing:

- Discuss the 7 elements of positive communication and determine if any were used during the introduction and activity portion of the session

- Be positive, be brief, label your feelings, offer an understanding statement, take partial responsibility, and offer to help

Application:

- How can knowing these elements help with future communication with your parents? Teachers? Other adults? Authority figures?

Summary: 


\section{Session 9: Bullying and Cyberbullying Prevention}

Introduction:

- Introduce yourself and purpose of the session- educating youth on appropriate social and relationship building skills

- Warm up: Toothpaste activity

- Ask a volunteer to come up and put toothpaste onto a piece of tape

- Then ask the student to put it back in the tube

- Explain the importance of bullying and gossip and that once you say something or put something out on the internet it can never be taken back

Activity:

- Divide the class into two groups

- Provide each group with a set of bullying cards (see next page)

- As a class, the students must develop a definition of each type of bullying

- The teams are then instructed to place the cards in order of least harmful to most harmful

Sharing:

- Each team must share their order of the cards and explain why they placed them in that order

Processing:

- Prompt the students with the following questions: what did you learn about the types of bullying? Do you know anyone who is/was bullied? If you saw someone being bullied what could you do?

Generalizing:

- Summarize key points discussed

Application:

- Prompt the students with the following questions: how could this effect someone academically? How could this be applied to the internet/cyberbullying? Does that make it better or worse? In what ways?

Summary: 


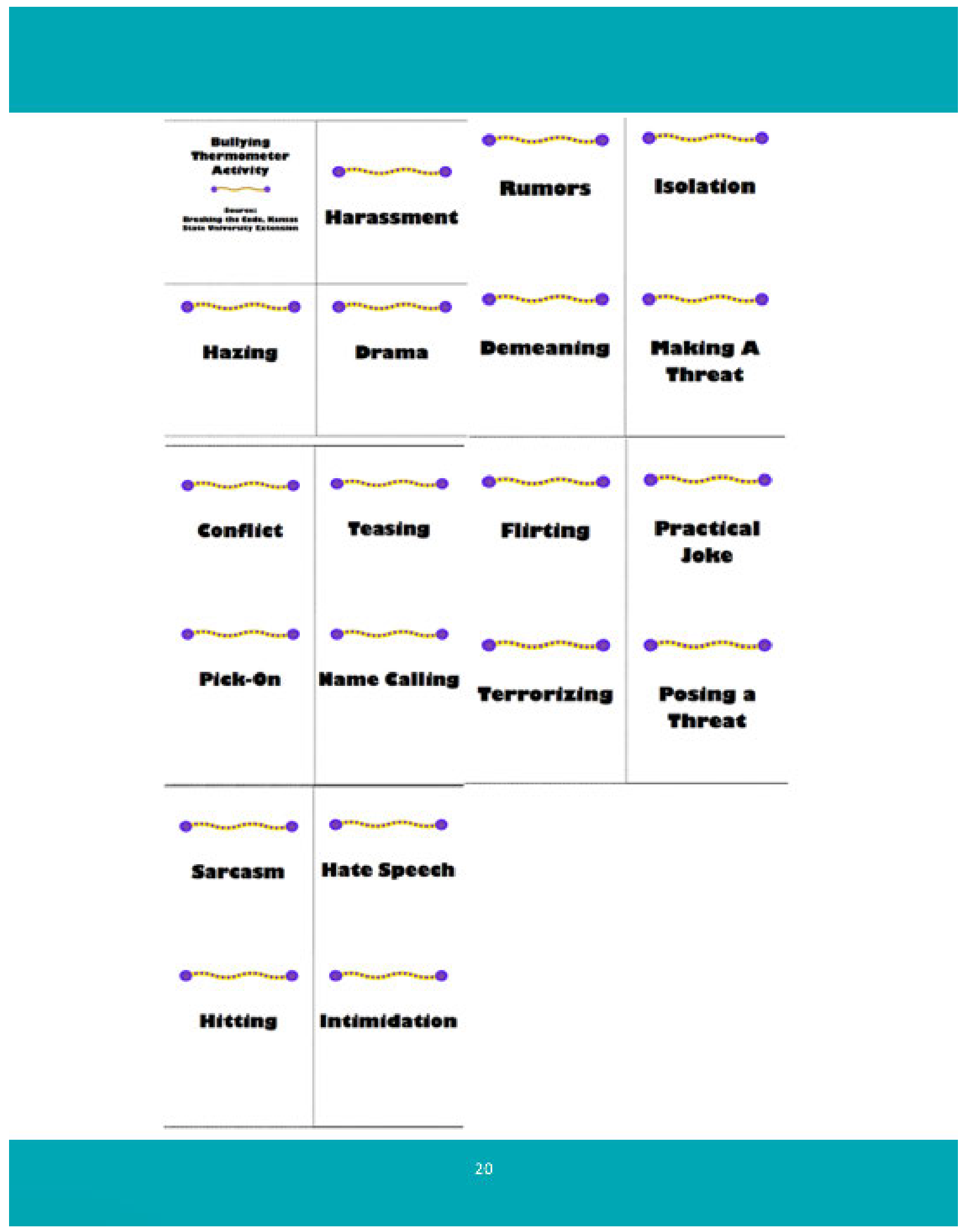

